\title{
Calcium Sulfate as a Scaffold for Bone Tissue Engineering: A Descriptive Review
}

\author{
Gabriela Fernandes, Vrushali Abhyankar*, Josanne M O’Dell \\ ${ }^{1}$ Former Periodontics resident and Clinical Assistant Instructor, Department of Periodontics and Endodontics, \\ Former Postdoctoral Fellow, Department of Oral Biology, SUNY Buffalo, Buffalo, New York, USA \\ ${ }^{2}$ Assistant Professor, Externship Director, Diplomate American Academy of Periodontology, The University of \\ Tennessee Health Science Center, Union AvenueMemphis \\ ${ }^{3}$ Associate Professor and Interim Program Director Department of EndodonticsUTHSC College of Dentistry, Union \\ Avenue, Memphis
}

Received: February 16, 2021; Accepted: February 25, 2021; Published: March 06, 2021

${ }^{*}$ Corresponding author: Vrushali Abhyankar, BDS.MDS.MS,Assistant Professor, Externship Director, The University of Tennessee Health Science Center S513, Dunn Dental Building 875, Union Avenue, Memphis, TN 38163; E-mail: vabhyank@uthsc.edu

\begin{abstract}
In regenerative approaches, scaffolds play a crucial role in defining the 3-D anatomical shape and microenvironment for regenerative cells, while maintaining space, favoring regeneration of new bone, and preventing soft tissue migration in the bony lesion. A variety of materials have been explored as scaffolds for bone tissue regeneration. Metals are generally inappropriate for such applications because they lack the desired degradability in a biological environment requiring a second surgery. Synthetic polymers can provide physical strength and engineered chemical properties however, they do not have optimal ease of handling or predictable biodegradation rate. In contrast to these scaffolds, calcium sulfate, also known as Plaster of Paris, is a highly biocompatible and biodegradable material that is one of the simplest synthetic bone-like grafts. It has been sued as a graft material in orthopedics and dentistry for more than one hundred years. The present review illustrates and examines current advances regarding calcium sulfate sources, various properties,scaffold forms, and clinical applications for bone tissue engineering.Additionally,it also describesNanocrystallinecalcium sulfate.
\end{abstract}

Keywords: Calcium sulfate; Gypsum; Plaster of Paris; Graft; Regeneration

\section{Introduction}

Tissue engineering isan interdisciplinary field that applies the principles of engineering and life sciences toward the development of biological substitutes that restore, maintain, or improve tissue function or a whole organ.Tissue engineering has also been defined as "understanding the principles of tissue growth and applying this to produce functional replacement tissue for clinical use [1,2]. It involves the use of a combination of cells, engineering and materials methods, and suitable biochemical and physio-chemical factors to improve or replace biological functions. While it was once categorized as a sub-field of biomaterials, having grown in scope and importance it can be considered as a field in its own right.

The field of Bone Tissue Engineering (BTE) was pioneered nearly three decades ago. Interest and progress in the BTE field have seen tremendous growth over the years, eversince the mid1980s. The field of BTE focuses on alternative treatment options that will ideally eliminate the obstacles of current clinically used treatments (i.e., donor site morbidity, limited availability, immune rejection, and pathogen transfer).

Bone grafts are utilized in a wide array of clinical settings to augment bone repair and regeneration. Bone defect repair using the tissue engineering approach is perceived as a better approach because the repair process may proceed with the patient's tissue by the time the regeneration is complete.Currently, the United States, as well as other countries worldwide, is experiencing an exceedingly high demand for functional bone grafts.

Engineered bone tissue has been viewed as a potential alternative to the conventional use of bone grafts, due to their limitless supply and no disease transmission. However, bone tissue engineering practices have not proceeded to clinical practice due to several limitations or challenges.Bone tissue engineering aims to induce new functional bone regeneration via the synergistic combination of biomaterials, cells, and factor therapy.Calcium sulfate (CS) possesses many of the characteristics of an ideal material for bone regeneration and is also an excellent agent as an osteoco nductive,osteoinductiveanosteogenic material. Despite its many virtues, it does have some shortcomings.

This paper aimed to highlight the properties of Calcium sulfate and the various combinations as well as clinical applications in the dental as well as the medical field and to provide future directions in research.

\section{Sources of Calcium sulfate}

A variety of sources are available for obtaining Calcium sulfate abundantly, which include both natural sources as well as being produced from other sources i.e. synthetic sources. 


\section{Natural Sources}

The main sources of Calcium sulfateinclude the Dihydrate gypsum and mineral selenite, bassanite, and hemihydrate commonly known as plaster of Paris. [3] There are several types of naturally occurring gypsum, and many industrial processes also produce gypsum as a by-product of their systems such as phosphoric acid and citric acid manufacture.

In nature, Gypsum and Anhydrite occur as beds or nodular masses up to a few meters thick. Gypsum is formed by the hydration of Anhydrite [4-6] The depth of hydration can range from the surface of the deposit down to three hundred meters, depending on temperature and pressure, topography, and the structure of the deposit. Anhydrite is often mined in conjunction with Gypsum but is comparatively limited in its technical applications. The content of Gypsum in sedimentary rock varies from $75 \%$ to $95 \%$, the rest being clay and chalk.

\section{Extracting Natural Gypsum}

Gypsum/Anhydrite are produced from open-cast mines, or underground mines using pillar and stall mining methods, that give extraction rates of up to $75 \%$. Gypsum is normally only screened to remove 'fines' (mainly mudstones), then crushed and finely ground. Gypsum/Anhydrite for cement manufacture is supplied in crushed form for further fine grinding with cement clinker[7].

\section{Processing Natural Gypsum}

When Gypsum ( CaSO4,2H 20) is ground to a powder and heated at $150^{\circ}$ to $165^{\circ} \mathrm{C}$, three- quarters of its combined water is removed producing hemihydrate plaster ( $\mathrm{CaSO} 4,1 / 2 \mathrm{H} \mathrm{20}$ ), commonly known as the 'Plaster of Paris' [8-11]. When this powder is mixed with water the resulting paste sets hard as the water recombines to produce Gypsum again. This process can be repeated almost indefinitely, with important implications for recycling [7, 12-15].

\section{Manufactured}

In addition to natural sources, Calcium sulfate is produced as a by-product in several processes as described.

\section{Flue-gas desulfurization}

In Flue-Gas Desulfurization(FGD), exhaust gases from fossil-fuel power stations and other processes (e.g. cement manufacture) are scrubbed to reduce their sulfur oxide content, by injecting finely ground limestone or lime. This produces an impure calcium sulfite which oxidizes on storage to Calcium sulfate[16, 17].

\section{Processing FGD Gypsum}

Of the flue gas desulphurization processes available, limestonebased scrubbing processes have proved the most popular[18]. The desulphurization process takes place in scrubbing towers in which the flue gases are brought into contact with an aqueous suspension containing powdered limestone or slaked quicklime as its alkaline component. The $\mathrm{SO}_{2}$ is washed out by the water, oxidized to ssulfatesSO3 in the aqueous solution, and precipitated with Calcium from the limestone/quicklime into Dihydrous Calcium sulfate $\left(\mathrm{CaSO}_{4}, 2 \mathrm{H}_{2} \mathrm{O}\right)$, Gypsum. The Gypsum crystals are separated from the suspension as a moist, fine crystalline powder with the aid of centrifuges or filters.

\section{Production of phosphoric acid from phosphate rock}

Calcium phosphate is treated with sulfuric acid and Calcium sulfate precipitates. Phosphoric Acid is considered a commodity chemical of which large quantities are used in the production of fertilizers and detergents. It is obtained by processes based on the decomposition of Phosphate minerals with Sulphuric Acid. TriCalcium Phosphate reacts with Sulphuric Acid to form Phosphoric Acid and Calcium sulfate. Most usually, the less soluble Calcium sulfate is separated from the Phosphoric Acid by filtration. The Calcium sulfate appears generally as Hemihydrate or Dihydrate, depending on process temperature conditions and the Sulphuric and Phosphoric Acid concentrations.

\section{Titanogypsum}

Titanium Dioxide is a white pigment and is, by far, the most important pigment in terms of quantity. World production of Titanium Dioxide is approximately 4 miotonnes/year, of which about one-half is produced by the Sulphate process, the other half by the Chloride process. Only the Sulphate process outputs Gypsum, of which a maximum of about $50 \%$, is the so-called 'White Gypsum', which can be considered for use by the Gypsum industry.

\section{Citrogypsum}

Citric Acid is a component found in almost all plant and animal species and is pivotal in the energy cycle of living organisms. Large quantities of Citric Acid for use in food, pharmaceutical, and detergent industries are produced by mycological fermentation of crude sugar solutions such as molasses[19]. To free Citric Acid from impurities such as proteins and sugars, it is precipitated with lime to Calcium Citrate and washed. Pure Citric Acid is then recovered by acidification with Sulphuric Acid and filtering off from the formed Gypsum. Technically, this Gypsum can be purified to a grade that can be processed by the Gypsum industry. Part of this Gypsum, however, is used as a filter aid to remove complex trace metals. It has a blue color due to the absorption of Ferric Hexacyanoferrate complexes which can only be removed by high-temperature calcination producing Anhydrite (usable by the cement industry)[20].

\section{Fluoroanhydrite}

For the production of Hydrofluoric Acid, the mineral Fluorspar or Fluorite is heated with Sulphuric Acid. As the reaction is normally conducted in dry conditions at elevated temperatures, the resulting Calcium sulfate is formed in the anhydrous form, Anhydrite. 


\section{Other Synthetic Gypsum}

Small amounts of Gypsum are recovered by the production of some organic acids like Tartaric, Lactic, Formi,c, and Oxalic Acid.

Additionally, all processes which end with the sub-product Sulphuric Acid are potential Gypsum producers. Neutralization of acidic effluents with lime or limestone yields Gypsum, for which the potential usage depends on the impurities remaining. Titanogypsum here is the classic example. The removal of Sulphates from brines with the help of lime produces Gypsum the high Magnesium content of this 'salt Gypsum' is one of the main obstacles to its use.

\section{Properties of Calcium sulfate}

Calcium sulfate is very common and often used as a laboratory and industrial chemical.In the form of $\gamma$-anhydrite (the anhydrous form), it is used as a desiccant hygroscopic substance that induces or sustains a state of dryness (desiccation) in its vicinity.

\section{Chemical Properties}

The chemical structure of Calcium sulfate can exist in three forms. Anhydrous Calcium sulfate $\left(\mathrm{CaSO}_{4}\right)$, which is available in two forms, known as insoluble anhydrite and soluble anhydrite.C calcium sulfate hemihydrate structure $\left(\mathrm{CaSO}_{4} \bullet \sim 0.5 \mathrm{H}_{2} \mathrm{O}\right)$, is known as Plaster of Paris; and Calcium sulfatedihydrate $\left(\mathrm{CaSO}_{4} \cdot 2 \mathrm{H}_{2} \mathrm{O}\right)$, which occurs naturally as gypsum.

\section{Anhydrous Calcium sulfate}

Also known as anhydrite,it is a mineral. The name anhydrite was given by A. G. Werner in 1804, because of the absence of water of crystallization, as contrasted with the presence of water in gypsum. When exposed to water, Anhydrite transforms to gypsum, $\left(\mathrm{CaSO}_{4} \cdot 2 \mathrm{H}_{2} \mathrm{O}\right)$ by the absorption of water. This transformation is reversible, with gypsum forming anhydrite by heating to $\sim 200^{\circ} \mathrm{C}$ under normal atmospheric conditions[22-25, 36-39, 60-63, 6568].

\section{Calcium sulfate hemihydrate $\left(\mathrm{CaSO}_{4} \cdot 2 \mathrm{H}_{2} \mathrm{O}\right)$}

When gypsum is heated to $110^{\circ} \mathrm{C}$, it loses water in a process known as the process of calcination.This results in the loss of water from Calcium sulfate leading to the formation of Calcium sulfate hemihydrate[26].

$\mathrm{CaSO}_{4} \cdot 2 \mathrm{H}_{2} \mathrm{O}+$ heat $\rightarrow \mathrm{CaSO}_{4} \bullet \frac{1}{2} \mathrm{H}_{2} \mathrm{O}+1 \frac{1}{2} \mathrm{H} 2 \mathrm{O}$ (steam).

\section{Calcium sulfate dihydrate}

Calcium sulfate hemihydrate is obtained by heating Calcium sulfate dihydrate to about 140-180 degrees celsius. When the hemihydrate is mixed with water, the material becomes rigid and relatively strong and forms the dehydrate in mildly exothermic reaction: $\mathrm{CaSO}_{4} \bullet 1 / 2 \mathrm{H}_{2} \mathrm{O}+1 \frac{1}{2} \mathrm{H}_{2} \mathrm{O} \rightarrow \mathrm{CaSO}_{4} \cdot 2 \mathrm{H}_{2} \mathrm{O}$.As the hemihydrate dissolves, a two-phase suspension of hemihydrate particles in a saturated aqueous solution is formed. When the solution becomes supersaturated with dihydrate, crystals nucleate in the suspension and form a precipitate. Nucleation and crystal growth continues until the solution is no longer saturated, leading to further dissolution of the hemihydrate. Alternating dissolution and precipitation continue, with the growth of existing crystals or nucleation of new crystals. [27] Proteins may lead to a delay in the setting time by preventing full hydration of the hemihydrate, inhibiting seed crystal formation, and forming complexes with the seed crystals. [28] Contamination of the CS with proteins (as might occur in a surgical wound site) may increase the setting time up to $200 \mathrm{~min}$.[29]

\section{Physical Properties}

With similar chemical structures, the three forms of Calcium sulfate differ in the physical structure with relation to crystal size,particle, and hardness.

\section{Anhydrite}

It is in the orthorhombic crystal system, with three directions of perfect cleavageparallel to the three planes of symmetry.The structure of anhydrite consists majorly of cleavage masses and well-developed crystals are rarely seen.The hardness is 3.5 and the specific gravity 2.9. The color is white, sometimes greyish, bluish, or purple with a white streak.It also possesses a vitreous to pearly luster [30-34].

\section{Calcium sulfate dihydrate}

Often occurring in nature, as flattened and transparent crystals, it has a crystal lattice structure which is described as being monoclinic.These crystals are found to contain anion water and hydrogen bonding.It is moderately water-soluble $(\sim 2.0-2.5 \mathrm{~g} / \mathrm{l}$ at $25^{\circ} \mathrm{C}$ ), and, in contrast to most other salts, it exhibits retrograde solubility, becoming less soluble at higher temperatures.

\section{Calcium sulfate hemihydrate}

It has two forms $-\alpha$ (alpha) and $\beta$ (beta) forms, which, although, possess similar chemical properties, and differ in several aspects [physical properties] including the crystal size, lattice structure, and surface area [35-38].

\section{a] Alpha- Calcium sulfate hemihydrate}

When gypsum is calcined under steam pressure in an autoclave at 120-130 degrees Celciusat 17lbs/sq.inch for 5-7 hours,then alpha Calcium sulfate hemihydrate is obtained.The process by which it is obtained is also known as wet calcination.The structure comprises cleavage fragments and rod and prismshaped crystals. The crystals generally comprise of small particle size $(0.3 \mathrm{~g} / \mathrm{g})$

\section{b] Beta- Calcium sulfate hemihydrate}

Manufactured by grinding and heating gypsum in an open kettle on a kiln at a temperature of 110-130 degrees Celsius by a process called dry calcination, they contain fibrous aggregates of fine crystals with capillary pores. They are then, ground to break- 
up the needle-likecrystals. Doingso improves the packing properties. .The particle size is larger, irregular, and porous, however, this reduces the hardness and strength. It is also hygroscopic and hence, must be stored in air-tight containers, since, upon exposure to a relative humidity which is greater than $70 \%$, it may tend to incorporate moisture and accelerate the setting reaction. It also consists of an aggregate of irregular crystals with interstitial capillary pores. Larger particle size $(0.6 \mathrm{~g} / \mathrm{g})[39,40]$. The difference in the structure between $\alpha$ form and $\beta$ form of Calcium Sulfate Hemihydrate is shown in Table 1.

\section{Mechanical Properties}

\begin{tabular}{|c|c|c|}
\hline Table 1: Difference in the structure between $\boldsymbol{\alpha}$ form and $\boldsymbol{\beta}$ form of Calcium sulphate hemihydrate \\
\hline & Alpha Form & Beta Form \\
\hline Process of Manufacturing & Wet Calcination & Dry Calcination \\
\hline Particle Size & Small, irregular and dense & More porous \\
\hline Porosity & Less porous & Less strength and hardness \\
\hline Mechanical property & More hardness and strength & .
\end{tabular}

Calcium sulfate is highly Biocompatible with human tissue. Studies have demonstrated a lack of significant host response post-implantation.[41]

\section{Biocompatibility and Degradibility}

Calcium sulfate has been employed as a substitute for bone graft in filling bone defects since 1892. Peltier cited the work of Dreesmann of the Trendelenburg clinic who observed complete healing in two out of three lesions with the bone defects which had been grafted with Calcium sulfate[42]. The early results were variable, presumably because of the inconsistent crystalline structure, purity, and quality of the Calcium sulfate[43]. In the 1960s and 1970,s Peltier and Peltier and Jones published extensive clinical data on the use of Calcium sulfate to fill bone defects and concluded that Calcium sulfate was a substitute thatthat enhanced the formation of bone and, for selected indications, gave results that were comparable with autograft.

The term Biocompatibility refers to the ability of a material to perform with an appropriate host response in a specific situation. The ambiguity of the term reflects the ongoing development of insights into how biomaterials interact with the humanbody and eventually how those interactions determine the clinical success of such material[44]. Biocompatibility is essentialfor implantable materials and is often the result of complex interactions at the host-material interface.A good biocompatible material should not elicit a host response after implantation [45].

Calcium sulfate (Plaster of Paris) acts as an osteoconductive scaffold and does not need to be removed after implantation due to its biodegradability [46]. Plaster of Paris has been introduced in the 19th century to treat bone defects in humans by Dreesmann, who filled bone with a slurry of plaster added with $5 \%$ of phenol. The extensive work of Peltier on Calcium sulfate led to the development of a medical-grade alpha-Calcium sulfate hemihydrate cylindrical pellet for the treatment of bony defects [47]. Experimental and clinical studies have shown its positive effect in the filling of dead bony spaces. The disadvantage of Calcium sulfate is its transient cytotoxic effect leading to inflammatory reactions, which was shown in several studies.
Implantation of Calcium sulfate into bone or soft tissue did not produce a foreign-body reaction and, by itself, did not induce bone. The formation of new bone occurred only when periosteum or bone was also present [48]. Peltier further concluded that the presence of Calcium sulfate in a wound did not inhibit the formation of bone and that it was removed from the site of implantation irrespective of whether or not new bone formation occurred. Infection in wounds containing Calcium sulfate was not complicated by sequestration of the material; it either drained out or was absorbed[49].

Many studies have reported a lack of such a significant response post-implantation with Calcium sulfate. Reports in the dental and orthopedic literature indicate that resorption of Calcium sulfate is rapid and complete when compared with other implantable regenerative materials. Investigators have reported that the resorption of Calcium sulfate is rapid and complete when compared with other implantable regenerative materials. [50]There is evidence that resorption of CS may be accelerated in osteoporosis, and this may affect the osteoconductivity of the material[51]

\section{Self-Setting Property}

Materials with self-setting properties have been exploited to augment human bone tissues and have drawn increasing attention in recent years. The transformation of Plaster of Paris $\left(\mathrm{CaSO}_{4} \cdot\right.$ $\left.1 / 2 \mathrm{H}_{2} \mathrm{O}, \mathrm{POP}\right)$ into Calcium sulfate dihydrate $\left(\mathrm{CaSO}_{4} \bullet 2 \mathrm{H}_{2} \mathrm{O}\right)$ via reaction with water has been used for many years to produce materials for bone augmentation, and the plaster continues to be the object of research and interest. The ability of rapid setting after filling the defect and the good biocompatibility of POP are the main reasons for its long history of clinical application[52]

Calcium sulfate hemihydrate $\left(\mathrm{CSH}, \mathrm{CaSO}_{4} \bullet 0.5 \mathrm{H}_{2} \mathrm{O}\right)$ has a long history of clinical application because of its properties of rapid setting in situ and good biocompatibility. In particular, when mixed with water, the $\mathrm{CSH}$ powder is converted into Calcium sulfate dihydrate (CSD, $\mathrm{CaSO}_{4} \cdot 2 \mathrm{H}_{2} \mathrm{O}$; gypsum) paste, which is regarded as one of the most successful bone cement, because it can undergo in situsettings after setting these defects, have good 
biocompatibility without inducing an inflammatory response, and promotes bone healing[53].

However, POP cement has some drawbacks, which significantly limit its clinical applications. First, after the process of self-setting, the solidified POP paste has a low and nearly constant mechanical strength, which fails to provide adequate long-term mechanical support for the defect site. Second, POP cement cannot form a chemical bond with bone tissue at the early stage of therapy because of its poor bioactivity. Moreover, the in vivo resorption rate of the POP cement is too fast, which may negatively affect bone regeneration [54].

Calcium sulfate has a prolonged setting time and incorporation of filler particles has been known to decrease the setting time from 30 mins to less than 3 minutes.Additionally,the proteins in the blood,too have demonstrated a role in prolonging the setting time[55]

\section{The function of calcium sulfate}

The precise mechanism by which Calcium sulfate promotes bone formation is still unknown; however,a probable list of mechanisms is described below:

\section{Altering pH level}

Osseous defects, whether from trauma or surgical intervention, all follow a similar healing pattern. Within minutes of defect formation, platelets collect at the site of the injury and adhere to the exposed collagen fibers[56]. The release of the platelet contents stimulates additional platelet aggregation and initiates a clot formation. This release also has a chemotactic effect and attracts various white blood cells (leukocytes) to the damaged tissues and an acute inflammatory response is initiated. Neutrophils and other leukocytes begin removing any bacteria, foreign material, and dead tissue via a process known as phagocytosis[57].The inflammatory response and other antigens in the wound also attract lymphocytes. These immune cells release cytokines, such as IL-1 and TNF- $\alpha$, which can have multiple actions on further physiologic responses. The disruption of the vascular supply, and the subsequent cellular reactions during the inflammatory and immune reactions, result in multiple changes in the local environment, including decreases in $\mathrm{pH}$, oxygen content, and the ionic concentrations for Calcium, phosphorus, potassium, and sodium. Concerning implant materials, chronic inflammation and foreign body reactions are associated with the development of a fibrous capsule around the implant. The goal of graft material is to aid in tissue healing [58].

Research on animals and humans with infrared spectroscopy confirm that once Calcium sulfate is implanted in the body, Calcium ions are combined with phosphate ions from the body fluids to form Calciumphosphate, which is osteoconductive and thus, in this way a network of biological apatite stimulates bone growth in the defect[59].The dissolution of Calcium sulfate and Calcium phosphate precipitation causes a local decrease in
pH.The $\mathrm{pH}$ decrease causes the demineralization of the bone surface exposing BMP releasing growth factors, TGF-b, and others contained in the bone matrix[60].Growth factors stimulate the formation of new blood vessels and bone formation. Another important event is Calcium sulfate which undergoes degradation in the defect and a local decrease in the $\mathrm{pH}$. This drop-in $\mathrm{pH}$ causes a demineralization wall defect with the release of bone growth factors. Recent studies indicate that there is increased expression of bone morphogenetic protein-2 (BMP-2), BMP-7, TGF-beta, and PDGF-BB in bone defects when Calciumsulfate is used as a bone graft[61].

These growth factors stimulate the formation and development of new bone. Originally Calcium sulfate was perceived only as filling defects, but many recent studies have demonstrated that Calcium sulfate is biocompatible, biodegradable, osteoconductive, safe, and non-toxic

The presence of Calcium sulfatealso increases the $\mathrm{pH}$ level, which results in the rapid resorption and degradation of Calcium sulfate. In the presence of a combination of CS with BMP,it led to the release of BMP which thus, enhanced bone formation activity[62-64] locally altered $\mathrm{pH}$ also may play a role in osteogenesis around CS implants. More specifically, increased acidity related to the dissolution of CS was postulated to cause localized demineralization, thereby releasing growth factors previously incorporated into the bone matrix. The release of biomolecules, such as the BMPs, would enhance osteoblastic differentiation of mesenchymal cells and consequently would increase bone formation [54].

\section{Promoting angiogenesis}

The soft-tissue healing of a wound creates a fibrous scar but bone is unique in its scarless regenerative capacity [65]. Repair of fractures by callus production occurs in four overlapping phases. Following damage to the musculoskeletal system, disruption of blood vessels leads to activation of the coagulation cascade and formation of a hematoma, which encloses the fracture area. Removal of the hematoma significantly attenuates repair, and transplantation of the hematoma produces new bone, consistent with the antigenic activity of the hematoma. Inflammatory cells, fibroblasts, and stem cells are recruited to the site, and new blood vessels are formed from pre-existing ones (i.e. angiogenesis). The inflammatory response is associated with pain, heat, swelling, and the release of several growth factors and cytokines that have important roles in repair [66]. Initially, granulation tissue forms at the ends of bones, gradually being replaced by fibrocartilage, in a manner seemingly related to the vascular pattern. Meanwhile, the periosteum undergoes direct bone formation, or intramembranous ossification, to create an external callus. Subsequently, the internal callus becomes mineralized with Calcium hydroxyapatite, to form a hard callus of woven bone. In the final, remodeling phase of bone regeneration, the large fracture callus is replaced by secondary lamellar bone; 
the size of the callus is reduced to that of pre-existing bone at the damage site, and the vascular supply reverts to a normal state. This temporal progression of repair can be recapitulated in animal models, such as those of long bone fractures [67].

The blood supply of mammalian long bones has been studied in many different bones and species. Generally, long bones receive blood from several groups of arteries: proximal/distal metaphyseal arteries, proximal/distal epiphyseal arteries, diaphyseal nutrient arteries, and periosteal arteries. Bone fracture results in disruption of the marrow architecture and blood vessels within and around the fracture site. During bone repair, the three components of the normal bone blood supply t bones and species. Generally, long bones receive blood from several groups of arteries. The newly generated blood supply to the callus and cortical bone appears to persist until the medullary blood supply is fully regenerated. The heterogeneity in vascularity after bone damage could help to explain local differences in bone formation in normal, delayed malunions.

Angiogenesis is the process by which new blood vessels sprout from established vessels. An increased expression of the mediators of the inflammation is present in inflamed tissues, and many of these factors can promote angiogenesis. Osteogenesis in skeletal regeneration has close links to the re- vascularization of the differentiating tissues. Regenerating tissues have higher metabolic needs and thus require a dense capillary network during the repair. Bone is, moreover, a richsource of angiogenic growth factors such as FGF and TGF, as well as osteogenic growth factors such as BMP.By promoting angiogenesis, a probable mechanism for the formation of bone by Calcium sulfate can be established, since studies have reported a microvascular density increase in treated defects $[65,68]$.

\section{The effect on osteogenesis}

Osteogenesis is the process of laying down new bone material by cells called osteoblasts. It is synonymous with bone tissue formation. Calcium sulfate plays a vital role in the formation of bone and not only as a filler in bone graft material. The mechanisms by which CS enhances bone formation have not been completely described or known. It has been suggested that CS particles bind to adjacent bone and then resorb, providing a mechanism to guide bone growth.Alternative explanations are possible and not mutually exclusive.

Strocchi et al. created bone defects in the tibiae of rabbits, which were then filled with CS granules or autogenous bone. Microvascular density was increased in the CS-treated defects, suggesting a positive effect on angiogenesis. The resultant increase in vascularity may, in part, account for the biological effects of CS implants [65].

Walsh et al. filled femoral cancellous defects with Calcium pellets and used immunohistochemistry to identify various growth factors in situ[69].Increased concentrations of bone morphogenetic protein (BMP)-2, BMP-7, transforming growth factor- $\beta$ (TGF- $\beta$ ), and Platelet-Derived Growth Factor (PDGF) were observed, all of which play a role in connective tissue regeneration. In the aggregate, these results suggest that CS does not act simply as inert filler, but it may play a more active role in osteogenesis[70].

\section{Migration of fibroblasts}

When human skin is damaged, the body initiates chemical and biological processes that help to repair the area that has been exposed to trauma. The normal mammalian in response to injury occurs in three overlapping but distinct stages: inflammation (which causes the removal of bacteria), re-epithelialization (by the processes of angiogenesis, collagen deposition, epithelialization, and wound contraction), and recovery with the remodeling phase[71].

Fibroblast cells play a guiding role in the second phase of wound healing that occurs 2-10 d after injury and is usually characterized by cellular proliferation and migration of different cell types[72]. Fibroblast cells are presumed to secrete fibroblast growth factor-7 (FGF7), a novel member of the FGFs family that binds exclusively to a splice variant of the FGF receptor, a transmembrane protein tyrosine kinase receptor, that is present on epithelial cells. The FGF7 expression at the wound site is restricted to dermal fibroblasts cells, and thus it is hypothesized to act in a paracrine manner, stimulate keratinocytes for cell proliferation and migration, and thereby affect wound reepithelialization[73].

The restoration of integrity to injured tissues by replacement of dead tissue with viable tissue. The process starts immediately after an injury and may continue for months or years, and is essentially the same for all types of wounds. Variations in wound healing are the result of differences in location, the severity of the wound, and the extent of injury to the tissues. Other factors affecting wound healing are the age, nutritional status, and general state of health of the animal and its body reserves and resources for the regeneration of tissue.

In healing by first intention (primary union), restoration of tissue continuity occurs directly, without granulation; in healing by second intention (secondary union), wound repair following tissue loss (as in ulceration or an open wound), is accomplished by closure of the wound with granulation tissue. This tissue is formed by the proliferation of fibroblasts and extensive capillary budding at the outer edges and base of the wound cavity. Healing by third intention (delayed primary closure) occurs when a wound is initially too contaminated to close and is closed surgically 4 or 5 days after the injury.

The insertion of drains can facilitate healing by providing an outlet for removing accumulations of serosanguineous fluid and purulent material, and obliterating dead space.The setting time of CS is altered in the presence of proteins in the blood, which 
results in the migration of fibroblasts thus leading to the primary wound closure and aiding in bone healing[74-76]

\section{Gene Expression}

Gene expression is the process by which information from a gene is used in the synthesis of a functional gene product. These products are often proteins, but in non-protein coding genes such as ribosomal RNA (rRNA), transfer RNA (t, RNA), or small nuclear RNA (snRNA) genes, the product is a functional RNA. The process of gene expression is used by all known life - eukaryotes (including multicellular organisms),prokaryotes (bacteria and archaea), and utilized by viruses - to generate the macromolecular machinery for life. Several steps in the gene expression process may be modulated, including the transcription, RNA splicing, translation, and post-translational modification of a protein.

Gene regulation gives the cell control over structure and function and is the basis for cellular differentiation, morphogenesis, and the versatility and adaptability of any organism. Gene regulation may also serve as a substrate for evolutionary change since control of the timing, location, and amount of gene expression can have a profound effect on the functions (actions) of the gene in a cell or a multicellular organism.

Osteoblast-like cells (MG-63) cultured with CS exhibited modified microRNA (miRNA) expression.miRNAs are non-coding RNAs of 19-23 nucleotides that can repress translation post-transcriptionally by degrading sequence-specific mRNA. This posttranslational repression may offer another mechanism by which CS influences osteoblast behavior. Another study reported that CS led to an increased AP activity which released Calcium ions thus enabling new bone formation[77-81]. The mechanism of action of calcium sulfate on bone formation is shown in Table 2.

\begin{tabular}{|c|c|}
\hline Table 2: Mechanism of action of Calcium sulphate on bone formation \\
\hline Property & Mechanism of Action \\
\hline Locally altered $\mathrm{pH}$ & Increased pH lead to increased dissolution rate of Calcium sulphate. \\
\hline Promoting Angiogenesis & Bone formation by increasing microvascular density \\
\hline Effect on gene expression & $\begin{array}{c}\text { Modified MiRNA expression. Posttranslational regression mechanism affects osteoblastic } \\
\text { behavior }\end{array}$ \\
\hline Osteogenesis & Plays a role in osteogenesis and not only as a filler \\
\hline Blood proteins affect setting time & Helps in primary closure by enabling the migration of fibroblasts \\
\hline Substrate for fibroblasts migration & Cells were able to migrate faster and better than compared to normal substrates in GTR \\
\hline
\end{tabular}

\section{Calcium sulfate Forms}

Calcium sulfate can exist and has been used either as solid forms or more preferably as paste or putty that sets during implantation. Minimally invasive injectable Calcium sulfate as an artificial bone substitute material has good prospects for clinical application. Although it is available in various forms, the most preferred form is the Putty. After injection, the paste hardens within minutes to form Precipitated Hydroxyapatite (PTH) or a carbonated apatite (CAP) of low crystalline order and small crystal size, very similar to the mineral phase of bone. The solubility of the injectable Calcium sulfate cement is expected to be similar to that of bone mineral.

\section{Injectable}

Calcium sulfate has a long-standing history in the treatment of bone voids secondary to trauma, infection, or neoplastic processes. Minimally-Invasive Injectable Graft injectable Calcium sulfate graft may be injected into surgically created osseous defects or bone defects secondary to traumatic injury. After hardening, the paste acts as temporary intraosseous support through which internal fixation may be placed.
The putty and paste form of Calcium sulfate is usually delivered via an injectable technique. Studies have reported that Calcium sulfate, when mixed with a glycerine carrier, results in the formation of a gel-like consistency, which can be delivered via large gauge needles. Mechanical properties exhibited by this material could provide a stronger osteoinductive scaffold and the resorption pattern after new bone incorporation for the core tract. Furthermore,the injection of the autologous bone marrow concentrate is intended to provide osteoinductive properties for bone regeneration in the necrotic area[35, 48, 77,82-87]. Table 3 shows a comparison between paste and putty form.

The resorption rate of the [injectable Calcium sulfate] ICS seems to be paralleled with the rate of bone ingrowth. However, more careful use of the ICS for optimal bone healing, and especially in the large or distal lesion of the extremities where the blood supply is poor,is recommended. Also, hardened Calcium sulfate can be drilled through, but it cannot be easily reamed through. Excessive reaming through ICS may cause thermal injury to the surrounding tissues, which may harm the process of bone ingrowth.

In a study done by Kelly et al,Fifteen patients with benign space- 
Table 3: Comparison between paste and putty form

\begin{tabular}{|c|c|c|}
\hline Form & Advantages & Disadvantages \\
\hline Paste & $\begin{array}{c}\text { Similar to mineral phase of bone. Small crystal size. Solubility is same as } \\
\text { bone mineral. }\end{array}$ & Does not remain in the defects. \\
\hline Putty & Improved handling and injectability. Better stability. Better than Paste. & Decreased stability \\
\hline
\end{tabular}

occupying lesions were treated with curettage and grafting with an injectable, surgical-grade, Calcium sulfate bone graft substitute. Bone healing was assessed postoperatively and defined as resorption of the bone graft substitute material and replacement with new bone formation. The grafted defects in 14 of the 15 patients showed complete incorporation of the graft material at an average of 8 weeks.

When compared to a Calcium sulfate paste, the putty has benefits of improved handling and injectability, as well as the ability to remain at a specific site when implanted. There appeared to be a slightly better intrusion of the putty into the interstices of the defects. The benefits of a putty form of Calcium sulfate over a paste are related to handling characteristics and the ability to remain where placed within a defect[85, 88-92]

\section{Preformed}

To regenerate bone, it is necessary to provide sufficient space or a "regeneration chamber" in which bone growth may occur. Creating a protected sanctuary may facilitate bone regeneration by protecting the developing bone tissue from excessive pressure from the overlying soft tissue. It is also necessary to block the ingress of cells which may proliferate and migrate faster than bone and may fill the space with tissues other than bone (e.g., epithelium or fibrous connective tissue).

Calcium sulfate (CS) has been used in bone regeneration for more than fifty years. It exhibits significant biocompatibility and is completely resorbed in a relatively short time. The microenvironment surrounding degrading CS is known to be rich in Calcium while eliciting a minimal inflammatory response. Calcium sulfate can be cast into various forms and can serve as a delivery vehicle for other biologic materials, such as antibiotics and growth factors.

Although CS is often mixed and placed into bone defects before setting, the use of preformed CS shapes has been reported by our group and others. Since it is impossible to create a rigid spacemaking device in situ such devices must befabricated beforehand. This also facilitates "loading" the prefabricated devices with biologically active agents such as antibiotics or osteotropic agents.

Preformed Calcium sulfate is indicated for use in bony voids or gaps that are notintrinsic to the stability of the bony structure. It should be gently packed into bonyvoids or gaps of the skeletal system (i.e., the extremities, spine, and pelvis). These defectsmay be surgically created osseous defects or osseous defects created from traumatic injury to the bone. The preformed block provides a bone void filler that resorbs and is replaced by the growth of new bone during the healing process. It also acts as a temporary space maintainer[54, 77,93].

\section{Combinations: [Bone regeneration]}

Although studies have established the superior regenerative properties of Calcium sulfate, efforts have been made to enhance this property by the addition of various other materials that have been demonstrated to possess bone regenerating capacity [Table 4].

\section{Autogenous bone}

Bone is composed of osteocytes surrounded by a rigid, highly calcified organic matrix. Although bone has good mechanical properties, it often undergoes damage or suffers defects resulting from tumor reconstruction, chronic infection, or traumatic bone loss. Large bone fracture defects or bone tumor resections are serious problems for bone surgery, though autografts and allografts have long been widely used for bone reconstructive surgery.The main drawback of autografts is donor shortage. For allograft, the problem is the potential risk of transmitting diseases and immunological response. Many synthetic bone graft materials, such as titanium alloy, ceramics, and polymers, have been used as bone substitute materials during the past decades. However, these substitute matrices have specific disadvantages in biocompatibility, degradability, osteogenic capability, and histochemical responses by the host tissue. It became necessary to find a promising alternative of autogenous bone for grafting applications.

In a comparative study by Deliberador et al, Class II furcation defects were treated with periodontal debridement, autogenous bone,and autogenous bone with a Calcium sulfate barrier.The histometric analysis was performed as part of the evaluation of the treatment. And no statistical significant differences were established between the three groups as far as the periodontal parameters were concerned,Additionally, studies conducted by MacNeil et al reported that synthetic graft materials can support new bone formation in surgically prepared defects when a comparative study on the healing response was performed using hydroxyapatite (HA), Calcium sulfate (CaSO4) plus autogenous bone, or a bioactive glass-ceramic on a rabbit model.

\section{Bioactive glass}

Despite its inherent brittleness, bioactive glass has several appealing characteristics as a scaffold material for bone tissue engineering. New bioactive glasses based on borate and 
borosilicate compositions have shown the ability to enhance new bone formation when compared to silicate bioactive glass. Boratebased bioactive glasses also have controllable degradation rates, so the degradation of the bioactive glass implant can be more closely matched to the rate of new bone formation. Bioactive glasses can be doped with trace quantities of elements such as $\mathrm{Cu}, \mathrm{Zn}$, and $\mathrm{Sr}$, which are known to be beneficial for healthy bone growth. In addition to the new bioactive glasses, recent advances in biomaterials processing have resulted in the creation of scaffold architectures with a range of mechanical properties suitable for the substitution of loaded as well as non-loaded bone. While bioactive glass has been extensively investigated for bone repair, there has been relatively little research on the application of bioactive glass to the repair of soft tissues. However, recent work has shown the ability of bioactive glass to promote angiogenesis, which is critical to numerous applications in tissue regeneration, such as neovascularization for bone regeneration and the healing of soft tissue wounds. Bioactive glass has also been shown to enhance neocartilage formation during in vitro culture of chondrocyte-seeded hydrogels and to serve as a subchondral substrate for tissue-engineered osteochondral constructs.

In a rat calvarium model used by Furlaneto et al.To compare BG with and without a CS barrier in an extraction site.Osteogenesis was evaluated by histomorphometry at 4 and 12 weeks. There was no significant difference in bone formation as compared with the ungrafted control sites. A similar approach used in extraction sockets in 16 patients demonstrated that the combination of bioglass with a CS barrier was beneficial for preserving alveolar ridge dimensions.

\section{Platelet Rich Plasma}

Although blood is mainly a liquid (called plasma), it also contains small solid components (red cells, white cells, and platelets.) The platelets are best known for their importance in clotting blood. However, platelets also contain hundreds of proteins called growth factors which are very important in the healing of injuries.

PRP is plasma with many more platelets than what is typically found in the blood. The concentration of platelet and, thereby, the concentration of growth factors - can be 5 to 10 times greater (or richer) than usual.

Within CS-Platelet, CS can activate the platelets present in the PRP without the need for an agonist, and carry and release growth factors in a time-dependent manner. Thus, CS-Platelet is a candidate biomaterial for bone regeneration because it can sustain over time the nourishment of the bone defects via the combinatorial delivery of Calcium and platelets' multiple biological factors.

In a study consisting of five mongrel dogs by Shi et al, extraction sockets were grafted using PRP alone and PRP in combination with Calcium sulfate. Grafting SGCS/PRP in fresh extraction sockets reduced alveolar ridge resorption and promoted the bone formation in this canine model. The addition of PRP to SGCS resulted in the enhancement of bone regeneration in the early phase of healing[94-96]In other studies, Implants placed in sockets grafted with MGCSH mixed with PRP showed less marginal bone loss after one year in comparison to those with collagen resorbable grafts.

\section{Chitosan and Alginate}

Chitosan is a carbohydrate biopolymer extracted from $\mathrm{N}$-acetylated chitin, a structural ingredient in the skeletons of crustacea (such as lobster, crab, crawfish) and the cell wall of fungi. Chitin and chitosan are absorbed as a form of monomer after being hydrolyzed by enzyme-like lysozyme [97]. Chitosan facilitates weight loss because it absorbs and combines with fat biologicallysoon, it plays a role in cholesterol control, improves the healing of connective tissues, and improves hemostasis. Besides, chitosan participates in wound healing and has the inductive ability for bone formation, as shown in various studies. In bone formation, chitosan is combined with the growth factorlike fibroblast growth factor (FGF), which is in the trabecular bone and helps the mitosis of matrix cells such as osteoblasts [98].

Mention has been made above of the use of chitosan and alginate composites of CS for use in the local delivery of chemotherapeutic agents. Similar composites have been proposed for use in bone regeneration, although these are in the early stages of development. Similar materials have been proposed the for delivery of antibiotics [99].

\section{Carboxymethylcellulose}

CarboxymethylCellulose (CMC) or cellulose gumis a cellulosederivative with carboxymethyl groups (-CH2$\mathrm{COOH}$ ) bound to some of the hydroxyl groups of the glucopyranosemonomers that make up the cellulose backbone. It is often used as its sodium salt, sodium carboxymethyl cellulose $[77,88]$.

CMC has been added to CS to improve its handling properties. Lewis et al.Improved the handling characteristics and mechanical properties of the Calcium sulfate. In particular, the addition of CMC produced a putty-like material with increased flexural and compressive strength [89]. The effect of CMC on bone regeneration has been studied by Reynolds et al., who reported that the addition of the polymer to a CS/demineralized bone matrix composite had no deleterious effect on osteogenesis in a rat calvarial model.[88]

\section{Calcium sulfate in combination with alginate}

Alginate is an anionic polysaccharide distributed widely in the cell walls of brown algae, where through binding with water it forms a viscous gum. In extracted form it absorbs water quickly; it is capable of absorbing 200-300 times its weight in water. Its color ranges from white to yellowish-brown. It is sold in filamentous, granular, or powdered forms [100]. 
In a study conducted by He et al on the effects of CS/alginate in the treatment of critical-sized craniofacial bone defects,the results demonstrated that injectable nCS/A paste is a biodegradable and biocompatible scaffold, and genetically engineered expression of BMP2 in MSCs in nCS/10\%A paste can provide an even more effective approach for repair of a critical-sized bone defect[64, 77].

Time-released hydroxyapatite/ $\beta$-triCalcium phosphate porosity provides sustained growth factor release, enhances ASC osteoinduction, and may result in better in vivo bone formation.

\section{Calcium sulfate impregnated with antibiotics}

One of the most dangerous possible complications in joint replacement is an infection due to bacteria adhere to the prosthesis surface making biofilm difficult to erase. The gold standard treatment consists of prosthesis removal, placement of antibiotic-impregnated cement spacer, and systemic antibiotics therapy. When the infection heals, a new prosthesis is implanted. The antibiotic-impregnated spacer is important to maintain the prosthesis space and to guarantee a locally high concentration of antibiotics. Best results during the first four weeks.

\section{Calcium sulfate with hydroxyapatite}

One example is the use of Calcium sulfate in conjunction with Hydroxyapatite (HA). The setting properties of Calcium sulfate allow it to be applied in a slurry form making it easier to handle and applied. HA is a Calcium phosphate mineral and is the primary constituent of human bones and teeth; it occurs in the boneas a major component between 60 and $70 \%$ and up to $98 \%$ in enamel. HA used in clinical service is similar to the chemical structure of the inorganic composition of human bone and thus has excellent biocompatibility in human studies. HA bone substitutes have been developed synthetically, derived from corals or algae, or naturally derived from bone mineral. The use of synthetic grafts in therapies for bone defects and bone-related diseases is gaining popularity, as the synthesized materials are readily available and do not possess the health risks associated with the biological grafts, e.g. risk of disease transmission[101].

HA was used in alveolar ridge augmentation, periodontal lesion filling blocks, and coatings in restorative dental and orthopedic implants. HA is an osteoconductive material, acting as a mineral scaffold into which new bone can grow; this is due to its properties that facilitate cell proliferation, migration, and new bone apposition. HA demonstrated excellent biocompatibility as the material was found to be nontoxic, non-allergenic, and noninflammatory after implantation in humans [102]. In particular, HA is generally well tolerated by the hard and soft tissues of the mouth and jaws. In vivo, HA undergoes some slight degradation after implantation, probably by gradual dissolution in tissue fluid as well as phagocytosis. HA is poorly reabsorbed in the body with good bone augmentation properties. HA can be used alone as a bone graft substitute as well as in combination with Calcium sulfate, chitosan, and other materials.

Calcium sulfate was used in conjunction with synthetic HA, coralline HA and presented good bone healing properties. Murali and co-workers presented new bone formation in an osteoporotic patient treated with Calcium sulfate, HA, and a growth hormone in the proximal femur. Abundant new bone formation is seen by SEM with a fine network of new bone between the HA particles. $\mathrm{X}$-ray microanalysis revealed that the newly formed bridges between HA particles were mineralized, having a similar chemical composition to bone. There were no morphological signs of intolerance of Calcium sulfate + HA. The results from this report suggest that a mixture of $\mathrm{HA}, \mathrm{CS}$, and $\mathrm{GH}$ is a potent stimulus to new bone formation.

Schindler used a composite graft containing 35\% Calcium sulfate hemihydrate and 65\% HA granules (mixed with autologous venous bone) to fill osteolytic defects in peri-articular areas of the knee. They showed that this composite graft can provide results equal to those achieved with autologous bone. The composite was well tolerated by all patients and no deformities were observed during the follow-up period (average of 4.5 years). Bone integrity and joint stability were re-established. Similar results were obtained by the same group (Schindler, 2008). They treated 13 patients with benign bone tumors in the lower limbs with a composite ceramic bone graft substitute containing 65\% HA granules and $35 \%$ Calcium sulfate hemihydrate (mixed with autologous venous bone). The composite did not disturb the proliferation of bone marrow or alter the normal growth pattern of bone in a locally aggressive benign bone tumor. Bone integrity and joint stability were regained in 11 out of the 13 patients. They concluded that composite ceramic bone graft substitutes containing a mixture of Calcium sulfate and HA can provide clinical results similar to those achieved through autologous bone grafting.

Stubbs et al (2004) examined the in vivo response of Calcium sulfate alone and as a carrier for coralline hydroxyapatite in an established bilateral corticocancellous defect model in rabbits. Defects were filled flush to the anterior cortex with a resorbable porous HA alone and in combination with Calcium sulfate slurry and examined at time points up to 52 weeks. Calcium sulfate improved the surgical handling of Pro Osteon $200 \mathrm{R}$ and played an important role in the ultimate closure of the cortical windows. Pro Osteon $200 \mathrm{R}$ supported new bone ingrowth into its porous domains even at the early time points while Calcium sulfate resorption was nearly complete by 6 weeks. Overall, clinical experience with HA alone or combined with Calcium sulfate provides additional information on the safety and clinical efficacy in use a bone graft in humans. The compressive strength and modulus of nHAC/CSD composites considerably altered with the variety of $\mathrm{L} / \mathrm{S}$ ratio and $\mathrm{nHAC}$ content. They increased with the decrease of nHAC content and L/S ratio. The reason can be that the addition of nHAC weakens the interactions among CSD molecules because the integrality of CSD materials is divided. CSD as a setting accelerator hardly affected the compressive 
properties of samples because it is not only the reactant of preparing CSH but also the final solidified product of CSH instead of a foreign body in this research.

\section{Calcium sulfate/gelatin composite material}

To develop high macroporous and degradable bone types of cement which can be used as the substitute for bone repairing and drug carriers, cross-linked gelatin microspheres (GMs) and Calcium sulfate dihydrate (CSD) powder were incorporated into Calcium phosphate bone cement (CPC) to induce macropores, adjust drug release and control setting time of alpha-TCP-liquid mixtures after degradation of GMs and dissolution of CSD. In this study, CSD was introduced into CPC/10GMs composites to offset the prolonged setting time caused by the incorporation of GMs, and gentamicin Sulphate (GS) was chosen as the model drug entrapped within the GMs. The effects of CSD amount on the cement properties, drug release ability, and final macroporosity after GM's degradation were studied in comparison with CPC/ GMcement. The resulting cement presented reduced setting time and increased compressive strength as the content of CSD below $5 \mathrm{wt} \%$. Sustained release of GS was obtained on at least 21 days, and release rates were found to be chiefly controlled by the GMs degradation rate. After 4 weeks of degradation study, the resulting composite types of cement appeared macroporous, degradable, and suitable compressive strength, suggesting that they have potential as a controlled local drug delivery system and for cancellous bone applications. A novel hybrid biomaterial composed of Calcium sulfate (CS) and gelatin (GEL) wasprepared with the potential of being used as bone filler or scaffold owing to itsosteoconduction. Such composite biomaterial, cross-linked or un-cross-linked,could provide a suitable absorbing rate and prevent the CS crystals from migratingfrom the implant for tissue engineering. The primary results showed that the CS/ CLGELcomposite filler could promote new bone in-growth[103, 104]

\section{Calcium sulfate with mesenchyme progenitor cells}

Current clinical therapies for critical-sized bone defects (CSBDs) remain far from ideal. Previous studies have demonstrated that engineering bone tissue using mesenchymal stem cells (MSCs) is feasible. However, this approach is not effective for CSBDs due to inadequate vascularization. In our previous study, we have developed an injectable and porous nano Calcium sulfate/alginate (nCS/A) scaffold and demonstrated that nCS/A composition is biocompatible and has proper biodegradability for bone regeneration. Here, we hypothesized that the combination of an injectable and porous nCS/A with bone morphogenetic protein 2 (BMP2) gene-modified MSCs and endothelial progenitor cells (EPCs) could significantly enhance vascularized bone regeneration. Our results demonstrated that delivery of MSCs and EPCs with the injectable nCS/a scaffold did not affect cell viability. Moreover, the co-culture of BMP2 gene-modified MSCs and EPCs dramatically increased osteoblast differentiation of
MSCs and endothelial differentiation of EPCs in vitro. We further tested the multifunctional bone reconstruction system consisting of an injectable and porous nCS/a scaffold (mimicking the nanoCalcium matrix of bone) and BMP2 genetically-engineered MSCs and EPCs in a rat critical-sized $(8 \mathrm{~mm})$ calvarial bone defect model. Our in vivo results showed that, compared to the groups of nCS/A, nCS/A+MSCs, nCS/A+MSCs+EPCs, and nCS/A+BMP2 gene-modified MSCs, the combination of BMP2 gene-modified MSCs and EPCs in nCS/A dramatically increased the new bone and vascular formation. These results demonstrated that EPCs increase new vascular growth and that BMP2 gene modification for MSCs and EPCs dramatically promotes bone regeneration. This system could ultimately enable clinicians to better reconstruct the craniofacial bone and avoid donor site morbidity. Investigators have established that the combination of Calcium sulfate with Mesenchymal progenitor cells can enhance bone regeneration around implants and also in critical-size defects[105]

\section{Calcium sulfate/PLLA Composite}

A study was conducted to characterize the dissolution, morphology, and chemical composition of a Calcium sulfate/ poly (L-lactic acid) (CS/PLLA) composite material before and after immersion in simulated body fluid (SBF). Twelve groups of experimental samples were prepared by coating CS pellets 1, 2, 3, or 4 times with one of three concentrations of a PLLA solution and wrapping them in the mesh; CS pellets for use as controls were similarly prepared but not coated. The PLLA coating added from 1 to $22 \%$ to the weight of experimental pellets; scanning electron microscopy revealed that the coating thickness ranged from 2 to 50 microns depending on the concentration of the coating solution and the number of coatings. All samples were immersed in SBF for up to 97 days. After immersion, the experimental coatings thinned out, small cracks and holes formed in the coating, and the coating became roughened. Mean dissolution rates for each of the 12 CS/PLLA groups were significantly lower than those of uncoated CS pellets; among CS/PLLA groups, dissolution rates varied according to the concentration of the coating solution and number of coatings. The half-life of pure CS pellets was 19 days whereas the half-life of CS/PLLA composite pellets ranged from 30 to 70 days. X-ray microprobe analysis of experimental pellets after immersion in SBF revealed that mineralization occurred in the CS portion of these pellets as well as on the coating; most of the mineral was Calcium phosphate, most of which was on the coating. Further studies will be required to confirm this composite's promise as a clinically effective osteoconductive material. The CS/PLLA composites were fabricated to form in situ scaffolds, which can both control the absorption rate of CS and prevent CS crystal particles from desquamation, which is important for its use as a bone graft. But this may be harmful to the surrounding tissue because heat is released during the transformation. However,further studies are required to warrant this[106-108] 


\section{Zinc-doped Calcium sulfate}

Compared to pure Calcium sulfate,more gypsum precipitates were formed in the zinc sulfate added samples with amorphology of thin, elongated, and rod-shaped crystals. The biological propertiesof the samples were analyzed in the terms of cell viability and cell activity on human osteosarcoma (G-292) using MTT assay and alkaline phosphatase (ALP)activity in the cell culture medium. The best-increased cell density and ALPactivity were achieved for the Calcium sulfate cement with a content of 0.74 wt \%Zn, whereas a toxic behavior was observed for the samples with $\mathrm{Zn}$ concentrations of more than 1.97\%[109]

\section{Nano calcium sulfate}

Although Calcium sulfate is considered as an excellent alternative to autogenous grafts since it is a biocompatible, osteoconductive,easily obtainable, and angiogenic bone graft that completely resorbs over some time and the difficulties faced with autogenous bone graft is procurement and the need for a second surgical site.Butthe major disadvantage of Calcium sulfates lies in their degradability activity.

\section{Need for Nano Calcium sulfate (nCS)}

Calcium sulfate (CS) undergoes fast degradation and resorption. For this reason,CS is often used by surgeons incombination with autogenous grafts,which again,involves difficulties in obtaining it as well as a second surgical site and donor site morbidity. The only disadvantage associated with Calcium sulfate is its fast degradation[110-113]. To overcome its disadvantage of rapid degradation, a nano-crystalline form of Calcium sulfate (nCS) wasdeveloped. nCS undergoes sustained degradation compared to traditional medical grade Calcium sulfate[64, 114]

\section{Advantages of nanoCalcium sulfate}

The unique microscopic structure of the nCS graft enables it to undergo controlled degradation over 16 weeks as compared to 4 to 6 weeks for traditional Calcium sulfate[115]. Because of the rapid degradation of traditional Calcium sulfate, many dentists use it only in combination with other bone grafts. The controlled degradation of nCS enables them to use it as a bone graft[65] As it undergoes degradation, it leaves behind a Calcium phosphate trellis. Osteoblasts attach to it and deposit bone along with it. This phenomenon occurs over 3-4 months in cases of bone defects grafted with nCS compared to 4-6 weeks for defects grafted with traditional Calcium sulfate. Additionally, other mechanisms discussed in the Introduction occur over a longer duration as well. As a result, nCS facilitates more effective bone formation compared to traditional Calcium sulfate[64, 77,116].

\section{Combinations}

Integration of nanoCalcium-deficient hydroxyapatite/multi (amino acid) copolymer (n-CDHA/MAC) and Calcium sulfate hemihydrate (CSH; CaSO4. 1/2H2O).Nano Calcium sulfate with particles in the range of 10-100 nanometer, will have enhanced physical properties such as a high surface area for growth factor adsorption with the potential for controlling the rate of release of the adsorbed material as well as superior mechanical strength for optimal osteoconductivity and resistance to fractures. The addition of macropores using alginate should not only enhance cell migration, but should also help in transport issues related to oxygen and nutrient delivery, waste removal, and protein transport[77]

\section{BMP2}

BMP-2 like other bone morphogenetic proteins,plays an important role in the development of bone and cartilage. It is involved in thehedgehog pathway, TGF beta signaling pathway, and cytokine-cytokine receptor interaction. It is involved also in cardiac cell differentiation and epithelial to mesenchymal transition.BMP-2 and BMP-7 are osteoinductive BMPs: they have been demonstrated to potently induce osteoblast differentiation in a variety of cell types.

Studies have demonstrated that the combination of an injectable and porous nCS/A with bone morphogenetic protein 2 (BMP2) gene-modified MSCs and endothelial progenitor cells (EPCs) could significantly enhance vascularized bone regeneration $[117,118]$. EPCs increase new vascular growth, and that BMP2 gene modification for MSCs and EPCs dramatically promotes bone regeneration. This system could ultimately enable clinicians to better reconstruct the craniofacial bone and avoid donor site morbidity for CSBDs [116].

\section{Applications}

\section{Bone defects}

Dreesman was the first to report the use of CS as a regenerative material in the late 19th century.CS rods to repair bone defects in a canine model and reported that CS did not promote bone growth unless covered by periosteum.When periosteum was present, however, there was the complete disappearance of the CS in 45-72 days and complete regeneration of the defects occurred in approximately 3 months.

\section{Oral Diseases}

Calcium sulfate is well tolerated by the tissues when used for the treatment of bone defects, guided tissue regeneration, and sinus augmentation in animals and humans, and the material was rapidly resorbed. In the 1960s, sterile Plaster of Paris pelletswase tested in a preliminary clinical study as an implant in infrabony periodontal lesions in 35 humans. Seventy nine percent of defects treated in this manner demonstrated regeneration of osseous tissue. There was no evidence of inflammation, edema, foreign body reaction, rejection of implant, or infection noted in any of the test sites in all 35 patients (Peltier, 1957). The results paralleled the report of Juillet (1976) who noted that Calcium sulfate was beneficial to osseous regeneration and that the material was well tolerated by hard and soft tissue in dental implant placement. 


\begin{tabular}{|c|c|c|c|c|}
\hline $\begin{array}{l}\text { Calcium sulphate } \\
\text { Combinations }\end{array}$ & Study & Advantages/Disadvantages & Uses & Authors \\
\hline Autogenous Bone & Mongrel Dogs & $\begin{array}{l}\text { Complete regeneration was not } \\
\text { achieved in the defects. }\end{array}$ & Class II furcation defects [periodontal] & $\begin{array}{l}\text { Deliberador } \\
\text { et al }\end{array}$ \\
\hline Allograft bone & Invitro studies & & & \\
\hline Bioactive glass & $\begin{array}{l}\text { Rat Calvarium } \\
\text { Model }\end{array}$ & $\begin{array}{l}\text { Beneficial in preserving alveolar } \\
\text { ridge dimension }\end{array}$ & Socket preservation & Furlaneto \\
\hline Platelet rich Plasma & Dogs & $\begin{array}{l}\text { Enhancement of bone } \\
\text { regeneration in the early stage of } \\
\text { healing }\end{array}$ & Alveolar ridge preservation & Shi et al \\
\hline Chitosan encapsulation & Invitro studies & $\begin{array}{l}\text { Synergistic effect with alginate. } \\
\text { Not cytotoxic. }\end{array}$ & Bone regeneration & D'ayala et al \\
\hline Carboxymethyl cellulose & Rat Calvarial & No greater advantages & & Reynolds et al \\
\hline Alginate & Rat Model & Biocompatible and biodegradable & Critical size bone defects & He X et al \\
\hline Antibiotics & Invitro studies & $\begin{array}{l}\text { Reduces infection. maintains } \\
\text { stability and gradually elutes }\end{array}$ & & Yang et al \\
\hline BMP & Invitro studies & Enhance stem cell osteoinduction & & Szpalski et al \\
\hline Hydroxyapatite & Invitro & $\begin{array}{l}\text { provide adequate environment for } \\
\text { cell adhesion and proliferation }\end{array}$ & & Hu NM et al \\
\hline Mesenchyme progenitor cells & Adult Dogs & $\begin{array}{l}\text { could be induced to osteoblasts } \\
\text { and adipocytes }\end{array}$ & $\begin{array}{l}\text { clinical reconstruction of bone } \\
\text { defects around immediate }\end{array}$ & Han X et al \\
\hline Gelatin composite & $\begin{array}{l}\text { Invitro and } \\
\text { rabbit radius } \\
\text { model }\end{array}$ & $\begin{array}{l}\text { human osteoblasts could attach } \\
\text { and spread on the surface of CS/ } \\
\text { CLGEL films }\end{array}$ & & Gao et al \\
\hline PLLA Composite & Invitro & & potential uses in bone repair & Gao et al \\
\hline Zinc & Invitro & $\begin{array}{c}\text { Beneficial at } 0.74 \mathrm{wt} \% \text { and toxic } \\
\text { effect at } 1.97 \% \text {. }\end{array}$ & & Hesaraki et al \\
\hline
\end{tabular}

Kim and Cho (2007) reported that Calcium sulfate pellets found very active on early consolidation in distraction osteogenesis versus control. In the Calcium sulfate group, the percentage of bone mineral density in the distracted area, compared with the normal mandible, was significantly higher than in the control group $(\mathrm{p}<0.05)$. The authors concluded that Calcium sulfate is a biocompatible osteoconductive material.

Sbordone and colleagues (2005) reported the successful treatment of a post- extraction maxillary buccal dehiscence in a patient. Calcium sulfate mixed with sterile $0.9 \% \mathrm{NaCl}$ to a putty-like consistency was packed into the defect, and 4 dental implants were placed in the edentulous ridge. Histologically, complete filling of the defect with mature, newly formed bone and complete resorption of the grafted material was noted five months later. The implants appeared to be successfully Osseo-integrated. Calcium sulfate root form implants for ridge preservation following tooth extraction produced significantly greater preservation of bone height and width than the ungrafted 
controls. Compared to a bovine-derived xenograft, allograft combined with putty induced significantly more vital bone in the experimental putty group (61\% versus $26 \%$ ) in humans. When used as a guided tissue regeneration barrier, together with demineralized freeze-dried bone allograft and Calcium sulfate composite graft, Calcium sulfate slowed epithelial and connective tissue ingrowth; furthermore, Calcium sulfate was successfully applied in periodontal defects, other osseous defects, and postextraction maintenance.

\section{Periodontal Intrabony defects}

A randomized, controlled, clinical study conducted by Kim et al to evaluate outcome following surgical implantation of an allogeneic, freeze-dried, demineralized bone matrix Calcium sulfate composite with a CS barrier in intrabony periodontal defects. Twenty-six patients contributing 26 deep intrabony defects completed the study. Thirteen patients received gingival flap surgery alone. There were no apparent differences between evaluations at 6 and 12 months post-surgery.There were no significant differences between groups in PD reduction and clinical attachment gain. However, gain in probing bone levels in deep intrabony periodontal pockets assessed by clinical parameters was greater than that observed by gingival flap surgery alone.

Calcium sulfate has been used in the treatment of periodontal intrabony defects in long-term clinical trials on humans and it demonstrated results that were at par when compared to bone regeneration achieved with autogenous bone graft.

\section{Furcation defects}

The effectiveness of a triCalcium phosphate, Plaster of Paris, and doxycycline composite graft to surgical debridement alone was compared in the treatment of Class II and Class III furcation defects in a small sample size. Results after 6 months indicated that sites treated with the composite graft had improved defect fill, defect resolution, probing depths, and clinical attachment levels when compared to the surgically debrided controls. Defect fill was 3.7 times greater in grafted sites and these sites were 4.0 times more likely to have $50 \%$ or greater defect fill. The effect of grafting was more pronounced in Class III defects where horizontal defect fill and gain of clinical attachment was achieved only in grafted sites. The Plaster of Paris functioned well as a binder, preventing particle scatter and facilitating graft retention[119]In a study by Conner et al, Calcium sulfate demonstrated success in regeneration procedures when there is advanced furcation bone destruction after root removal[120]

\section{Guided Bone Regeneration}

The concept of guided tissue regeneration was first introduced in the literature more than 20 years ago. Since then, the concept has evolved to include different materials and different techniques. In a case report by White et al, a multidisciplinary approach was performed to treat external root resorption and osseous defect.
A combined approach utilizing MTA for root surface repair, and DFDBA and Calcium sulfate to address an associated osseous lesion proved to be a viable modality in the treatment of chronic endodontic/periodontal lesions[121] In another three years randomized trial, whereCalcium sulfate was used in the guided bone regeneration in periodontal osseous defects.it demonstrated qualities as being a completion material, space maintainer, the vehicle for a controlled release of certain drugs, associated with other graft materials[122] Additionally,several other studies have supported the use of CS in guided bone regeneration[123-125]

\section{Drug Delivery}

In addition to its space-filling and barrier functions, CS has been investigated as a local delivery vehicle for therapeutic agents, such as antibiotics, small molecule drugs, and growth factors. CS can serve as a delivery system for various antimicrobial agents. Although it does not possess antimicrobial activity itself, there is some preliminary evidence that suggests that the material may not be a good substrate for the growth of some pathogens, including Porphyromonasgingivalils.It seems likely, therefore, that CS may be of particular use in bone regeneration sites where the infection is possible or likely.

Various combinations of CS with drugs have been utilized in the treatment of osseous defects,of which are a bovine osteogenic factor,plasma protein factor,fibroblast growth factor,tgfalpha,cephalexin,doxycycline are a few.The use of a drug-loaded plaster in the treatment of infected bony defects has been supported by various studies without any evidence of a local or systemic adverse effect. The property of resorbability endows Calcium sulfate the ability to be used as an implant device loaded with various materials, e.g. antibiotics, pharmacological agents, and growth factors. Absorbable Calcium sulfate pellets impregnated with antibiotics are currently widely used, e.g., for the management of diabetic foot infections (Armstrong et al., 2001). Historically, using Calcium sulfate as a carrier material for antiseptics and antibiotics began as early as 1928. The local delivery of antibiotics was initiated in the 1930s with the introduction of sulphonamide.

Kovacevic (1953) implanted Calcium sulfate cylinders containing penicillin and sulphonamide powder into patients suffering from haematogenic osteomyelitis. The author reported primary healing of the operative wounds, slow absorption and disappearance of the plaster, and, finally, bony regeneration through the area of the defect. The introduction of antibiotic-impregnated cement in the 1970 s increased the concentration of antimicrobial compounds in a local area, augmenting the use of systemic-parental antibiotics for bone infection therapy. Finally, bone graft substitute materials containing growth factors in their composition, including recombinant human bone morphogenetic protein-2 (BMP-2) and rhBMP-7 (OP-1), demonstrate osteoinduction in clinical application. 


\section{Endodontic Surgery}

The ultimate goal in endodontic microsurgery is the predictable regeneration of periapical tissues. One of the main concerns in treating an endodontically treated tooth which has a throughand-through osseous defect is that incomplete bone healing may be inevitable, however, CS has proved to be of success in endodontic microsurgery $[126,127]$

\section{Socket Preservation}

Dimensional changes after tooth extraction often result in bone resorption that complicates restorations with an implant or traditional prostheses. Preservation of alveolar dimensions after a tooth extraction is crucial to achieving optimal esthetic and functional prosthodontic results. Also, with the increasingly frequent use of dental implants to replace nonrestorable teeth, preservation of the existing alveolus is essential to maintain adequate bone volume for placement and stabilization of the implants. Atraumatic extraction and socket preservation techniques have been introduced to minimize bone resorption after tooth extraction.Recently CS is being used as a bone graft material in the preservation of socket post-extraction.

\section{Sinus Augmentation}

Regeneration and preservation of bone after the extraction of a tooth are necessary for the placement of a dental implant. The goal is to regenerate alveolar bone with minimal postoperative pain. Medical Grade Calcium Sulfate Hemihydrate (MGCSH) can be used alone or in combination with other bone grafts; it improves graft handling characteristics and particle containment of particle-based bone grafts.Results have demonstrated an increase in the bone leading to successful placement of implants. Calcium sulfate cement was used to regenerate bone around endosseous dental implants in humans during maxillary sinus augmentation. Pecora and colleagues (1998) performed a series of studies and wrote a case report on Calcium sulfate as a graft material for the maxillary sinus. The clinical and radiographic evaluation showed that it was possible to achieve the formation of new tissue that was quantitatively and qualitatively suitable for endosseous implant placement. Initially, the authors described the successful integration of 4 implants in 2 patients 9 months after Calcium sulfate hemihydrate (SurgiPlasterTM) had been used as a graft material. Following this successful case report, De Leonardis and Pecora (1999) performed a prospective, longitudinal trial consisting of a pilot group of 15 sinuses in 12 healthy patients requiring maxillary sinus augmentation for implant placement and a test group of 50 sinuses in 45 patients. The groups differed only in the technique of Calcium sulfate application (SurgiPlasterTM), as described below. Implants were then placed and followed for at least 1 year. The overall success rate for the 130 placed implants 1-yearpost-implantation was high (98.5\%). Histological analysis indicated type II or III bone in all specimens. In a subsequent publication, De Leonardis and Pecora (2000) compared the histological differences in the pilot and test groups. In the test groups, the authors placed preformed Calcium sulfate with a putty-like consistency in a stratified manner ( $\mathrm{N}=65$ sinuses), which allowed each layer to harden as the next layer was placed. They stated that this allowed a denser fill and slowed the resorption of the material after sinus augmentation. As a result, the test group showed a mean bone concentration of $55.54 \%( \pm 19.82)$, while the control group showed a mean histomorphometric bone density of $34.25 \%( \pm 10.02)$. The authors further noted that both of these measurements compared favorably with other studies on bone concentration in grafted maxillary sinuses.

Guarnieri and co-workers (2007) used SurgiplasterTM in sinus augmentation. The study evaluated the radiographic and histological results using granular medical-gradeCalcium sulfate hemihydrate (SurgiplasterTM) as a grafting material in sinuses. Forty tooth implants were implanted along with grafting material in 10 patients, representing 15 sinuses. Radiographs were taken before sinus augmentation, monthly until 6 months postoperatively, 9 and 12 months after implant placement, and annually thereafter. Bone biopsies were harvested from all patients for histological and histomorphometric evaluation. The author concluded that SugiplasterTMCalcium sulfate when used as grafting material in sinus lift procedures may lead to appropriate Osteointegration of dental implants and can be used to create adequate bone volume before implant placement.

\section{Medical}

\section{Treatment of non-unions}

Medical grade Calcium sulfate increases the volume of graft material, facilitates bone formation, and is safe in the treatment of non-unions and fractures with osseous defects[128]

\section{Metaphyseal bone defects}

Calcium sulfate cement has displayed success in the treatment of metaphyseal bone defects, when tested on humans inperiarticular fractures--distal radial, tibial plateau, humeral head, and calcaneal fractures[129]

\section{Long bone defects due to surgical tumor excision}

Calcium sulfate has a long-standing history in the treatment of bone voids secondary to trauma, infection, or neoplastic processes. Minimally-Invasive Injectable Graft injectable Calcium sulfate graft may be injected into surgically created osseous defects or bone defects secondary to traumatic injury. After hardening, the paste acts as temporary intraosseous support through which internal fixation may be placed [86]

Unicameral bone cystUnicameral bone cysts are benign bone lesions commonly seen in pediatric patients. CS has been used in the treatment of these cysts [130] 


\section{Guidelines for future studies [proposed hypothesis]}

Cs has already depicted success in the bone regeneration of Class II and Class III furcation defects,which are usually difficult to treat.Hence more studies can be directed towards utilizing CS in regenerating bone in these furcation defects. Saving hopeless teeth did not seem possible,but studies have proved otherwise. Hence future trials can aim at attempting to save periodontally compromised teeth[131].Drug delivery may appear to be another good option for further studies on CS,after reviewing the available drug CS combinations.More erudite devices might employ CS forms to release drugs in a pulsatile fashion[122, 132-148].

\section{References}

1. MacArthur BD, Oreffo RO. Bridging the gap. Nature. 2005;433(7021):19.

2. Langer R, Vacanti JP. Tissue engineering. Science. 1993;260(5110):920926.

3. Parker AC, Smith JK, Courtney HS, Haggard WO. Evaluation of two sources of calcium sulfate for a local drug delivery system: a pilot study. Clinical orthopaedics and related research. 2011;469(11):3008-3015.

4. Moon YH, Kim JG, Ahn JS, Lee GH, Moon HS. Phosphate removal using sludge from fuller's earth production. Journal of hazardous materials. 2007;143(1-2):41-48.

5. Murtoniemi T, Nevalainen A, Hirvonen MR. Effect of plasterboard composition on Stachybotrys chartarum growth and biological activity of spores. Applied and environmental microbiology. 2003;69(7):37513757.

6. Okabe S, Odagiri M, Ito T, Satoh H. Succession of sulfur-oxidizing bacteria in the microbial community on corroding concrete in sewer systems. Applied and environmental microbiology. 2007;73(3):971-980.

7. Hoft H. [Synthetic or natural gypsum? Difference is in the source]. Das Dental-Labor Le Laboratoire dentaire The Dental laboratory. 1989;37(2):183-187.

8. Qin Q Mi ZM, Zhao YS, Feng XP, Zeng HX. [A discussion on the concentration assay for hemihydrate gypsum in plaster of paris bandage-viscose form]. Zhongguo Yi Liao Qi Xie Za Zhi. 2009;33(1):62-63.

9. Chandara C, Azizli KA, Ahmad ZA, Sakai E. Use of waste gypsum to replace natural gypsum as set retarders in portland cement. Waste management. 2009;29(5):1675-1679.

10. Springmann W, Vieira DF. Changes in physical properties of joined gypsum fragments. The Journal of prosthetic dentistry. 1977;37(1):50-56.

11. Sendigere D. Plaster of Paris. The history of gypsum. The Nursing journal of India. 1974;65(5):139-140.

12. Kort HS, Schober G, Koren LG, Scharringa J. Mould-devouring mites differ in guanine excretion from dust-eating Acari, a possible error source in mite allergen exposure studies. Clinical and experimental allergy. Journal of the British Society for Allergy and Clinical Immunology. 1997;27(8):921-925.

13. Lu HY. Hydrochemistry and boron isotopes as natural tracers in the study of groundwaters from North Chianan Plain, Taiwan. Isotopes Environ Health Stud. 2013.

14. Montero A, Tojo Y, Matsuo T, Matsuto T, Yamada M, Asakura H, et al. Gypsum and organic matter distribution in a mixed construction and demolition waste sorting process and their possible removal from outputs. Journal of hazardous materials. 2010;175(1-3):747-753.

15. Myatt TA, Allen JG, Minegishi T, McCarthy WB, Stewart JH, Macintosh $\mathrm{DL}$, et al. Assessing exposure to granite countertops--Part 1: Radiation. J Expo Sci Environ Epidemiol. 2010;20(3):273-280.

16. Akiho H, Ito S, Matsuda H, Yoshioka T. Elucidation of the mechanism of reaction between S208(2-), Selenite and $\mathrm{Mn} 2+$ in aqueous solution and limestone-gypsum FGD liquor. Environmental science \& technology. 2013;47(19):11311-11317.

17. Bryant RB, Buda AR, Kleinman PJ, Church CD, Saporito LS, Folmar GJ, et al. Using flue gas desulfurization gypsum to remove dissolved phosphorus from agricultural drainage waters. Journal of environmental quality. 2012;41(3):664-671.

18. Wu XQ, Wu ZB. Modification of FGD gypsum in hydrothermal mixed salt solution. Journal of environmental sciences. 2006;18(1):170-175.

19. Cornelis G, Poppe S, Van Gerven T, Van den Broeck E, Ceulemans M, Vandecasteele C. Geochemical modelling of arsenic and selenium leaching in alkaline water treatment sludge from the production of non-ferrous metals. Journal of hazardous materials. 2008;159(23):271-279.

20. Li X, He C, Bai Y, Ma B, Wang G, Tan H. Stabilization/solidification on chromium (III) wastes by C(3)A and C(3)A hydrated matrix. Journal of hazardous materials. 2014;268:61-67.

21. Deer H, \& Zussman. An Introduction to the Rock Forming Minerals. 2nd Edition ed. England: Pearson Education Limited. 1992.

22. Bayuseno AP, Schmahl WW. Understanding the chemical and mineralogical properties of the inorganic portion of MSWI bottom ash. Waste management. 2010;30(8-9):1509-1520.

23. Mirwald PW. Experimental study of the dehydration reactions gypsum-bassanite and bassanite-anhydrite at high pressure: indication of anomalous behavior of $\mathrm{H}(2) \mathrm{O}$ at high pressure in the temperature range of 50-300 degrees $\mathrm{C}$. The Journal of chemical physics. 2008;128(7):074502.

24.Cernik RJ, Barnes P, Bushnell-Wye G, Dent AJ, Diakun GP, Flaherty JV, et al. The new materials processing beamline at the SRS Daresbury, 
MPW6.2. Journal of synchrotron radiation. 2004;11(Pt 2):163-170.

25. Mori T. Study of gypsum-bonded casting investments. Part 1. Australian dental journal. 1993;38(3):220-224.

26. KJ A. Gypsum products. St. Louis, MO: Saunders; 2003.

27. Couri CJ, Maze GI, Hinkson DW, Collins BH, 3rd, Dawson DV. Medical grade calcium sulfate hemihydrate versus expanded polytetrafluoroethylene in the treatment of mandibular class II furcations. Journal of periodontology. 2002;73(11):1352-1359.

28. Guarnieri R, Aldini NN, Pecora G, Fini M, Giardino R. Medial-grade calcium sulfate hemihydrate (surgiplaster) in healing of a human extraction socket--histologic observation at 3 months: a case report. The International journal of oral \& maxillofacial implants. 2005;20(4):636641.

29. Guarnieri R, Pecora G, Fini M, Aldini NN, Giardino R, Orsini G, et al. Medical grade calcium sulfate hemihydrate in healing of human extraction sockets: clinical and histological observations at 3 months. Journal of periodontology. 2004;75(6):902-908.

30. Nightingale M, Mayer B. Identifying sources and processes controlling the sulphur cycle in the Canyon Creek watershed, Alberta, Canada. Isotopes Environ Health Stud. 2012;48(1):89-104.

31. Motlep R, Sild T, Puura E, Kirsimae K. Composition, diagenetic transformation and alkalinity potential of oil shale ash sediments. Journal of hazardous materials. 2010;184(1-3):567-573.

32. Swaenen M, Stefaniak EA, Frost R, Worobiec A, Van Grieken R. Investigation of inclusions trapped inside Libyan desert glass by Raman microscopy. Analytical and bioanalytical chemistry. 2010;397(7):26592665.

33. Pulvirenti AL, Needham KM, Adel-Hadadi MA, Marks CR, Gorman JA, Shettel DL, et al. Acid generation upon thermal concentration of natural water: the critical water content and the effects of ionic composition. J Contam Hydrol. 2009;109(1-4):62-81.

34. Aranberri-Askargorta I, Lampke T, Bismarck A. Wetting behavior of flax fibers as reinforcement for polypropylene. Journal of colloid and interface science. 2003;263(2):580-589.

35. Cortez PP, Silva MA, Santos M, Armada-da-Silva P, Afonso A, Lopes MA, et al. A glass-reinforced hydroxyapatite and surgical-grade calcium sulfate for bone regeneration: In vivo biological behavior in a sheep model. Journal of biomaterials applications. 2012;27(2):201-217.

36. Saitoh T, Yanagita T, Shiraishi S, Yokoo H, Kobayashi H, Minami S, et al. Down-regulation of cell surface insulin receptor and insulin receptor substrate-1 phosphorylation by inhibitor of 90-kDa heat-shock protein family: endoplasmic reticulum retention of monomeric insulin receptor precursor with calnexin in adrenal chromaffin cells. Molecular pharmacology. 2002;62(4):847-855.
37. Yamaguchi M, Segawa Y, Shimokawa N, Tsuzuike N, Tagashira E. Inhibitory effect of beta-alanyl-L-histidinato zinc on bone resorption in tissue culture. Pharmacology. 1992;45(5):292-300.

38. Stevens RD, Lack L, Killenberg PG. Calcium binding by monosulfate esters of taurochenodeoxycholate. Journal of lipid research. 1991;32(4):621-627.

39. Nilsson M, Zheng MH, Tagil M. The composite of hydroxyapatite and calcium sulphate: a review of preclinical evaluation and clinical applications. Expert review of medical devices. 2013;10(5):675-684.

40. Nilsson M, Wielanek L, Wang JS, Tanner KE, Lidgren L. Factors influencing the compressive strength of an injectable calcium sulfate-hydroxyapatite cement. Journal of materials science Materials in medicine. 2003;14(5):399-404.

41. Chen H, Cui X, Yu X, Tian X, Zhang B, Tang P, et al. Effects of chitosancoated pressed calcium sulfate pellets combined with recombinant human bone morphogenetic protein 2 on bone formation in femoral condyle-contained bone defects. The Journal of craniofacial surgery. 2010;21(1):188-197.

42. Larsson S, Hannink G. Injectable bone-graft substitutes: current products, their characteristics and indications, and new developments. Injury. 2011;42 Suppl 2:S30-34.

43. Bauer TW, Togawa D. Bone graft substitutes: towards a more perfect union. Orthopedics. 2003;26(9):925-926.

44. Orsini G, Ricci J, Scarano A, Pecora G, Petrone G, Iezzi G, et al. Bonedefect healing with calcium-sulfate particles and cement: an experimental study in rabbit. Journal of biomedical materials research Part B, Applied biomaterials. 2004;68(2):199-208.

45. Qi X, Li H, Qiao B, Li W, Hao X, Wu J, et al. Development and characterization of an injectable cement of nano calcium-deficient hydroxyapatite/multi(amino acid) copolymer/calcium sulfate hemihydrate for bone repair. International journal of nanomedicine. 2013;8:44414452.

46. Kelly CM, Wilkins RM, Gitelis S, Hartjen C, Watson JT, Kim PT. The use of a surgical grade calcium sulfate as a bone graft substitute: results of a multicenter trial. Clinical orthopaedics and related research. 2001(382):42-50.

47. Kim JH, Oh JH, Han I, Kim HS, Chung SW. Grafting using injectable calcium sulfate in bone tumor surgery: comparison with demineralized bone matrix-based grafting. Clinics in orthopedic surgery. 2011;3(3):191-201.

48. Shih TC, Chang WJ, Yang JC, Feng SW, Lin CT, Teng NC. In vivo evaluation of resorbable bone graft substitutes in mandibular sockets of the beagle. Journal of biomedical materials research Part A. 2012;100(10):2726-2731. 
49. Thomas MV, Puleo DA, Al-Sabbagh M. Calcium sulfate: a review. Journal of long-term effects of medical implants. 2005;15(6):599-607.

50. Jepegnanam TS, von Schroeder HP. Rapid resorption of calcium sulfate and hardware failure following corrective radius osteotomy: 2 case reports. The Journal of hand surgery. 2012;37(3):477-480.

51. Payne JM, Cobb CM, Rapley JW, Killoy WJ, Spencer P. Migration of human gingival fibroblasts over guided tissue regeneration barrier materials. J Periodontol. 1996;67(3):236-244.

52. Shih TC, Teng NC, Wang PD, Lin CT, Yang JC, Fong SW, et al. In vivo evaluation of resorbable bone graft substitutes in beagles: histological properties. Journal of biomedical materials research Part A. 2013;101(8):2405-2411.

53. Hu NM, Chen Z, Liu X, Liu H, Lian X, Wang X, et al. Mechanical properties and in vitro bioactivity of injectable and self-setting calcium sulfate/nano-HA/collagen bone graft substitute. Journal of the mechanical behavior of biomedical materials. 2012;12:119-128.

54. Chen Z, Liu H, Liu X, Cui FZ. Injectable calcium sulfate/mineralized collagen-based bone repair materials with regulable self-setting properties. Journal of biomedical materials research Part A. 2011;99(4):554563.

55. He Y, Gao J, Li X, Ma Z, Zhang Y, Li M, et al. Fabrication of injectable calcium sulfate bone graft material. Journal of biomaterials science Polymer edition. 2010;21(10):1313-1330.

56. Bulo RE, Siggel L, Molnar F, Weiss H. Modeling of bovine type-I collagen fibrils: interaction with pickling and retanning agents. Macromolecular bioscience. 2007;7(2):234-240.

57. Salbach-Hirsch J, Ziegler N, Thiele S, Moeller S, Schnabelrauch M, Hintze V, et al. Sulfated glycosaminoglycans support osteoblast functions and concurrently suppress osteoclasts. Journal of cellular biochemistry. 2014;115(6):1101-1111.

58. Robion FC, Doize B, Boure L, Marcoux M, Ionescu M, Reiner A, et al. Use of synovial fluid markers of cartilage synthesis and turnover to study effects of repeated intra-articular administration of methylprednisolone acetate on articular cartilage in vivo. Journal of orthopaedic research : official publication of the Orthopaedic Research Society. 2001;19(2):250-258.

59. Paolantonio M, Perinetti G, Dolci M, Perfetti G, Tete S, Sammartino G, et al. Surgical treatment of periodontal intrabony defects with calcium sulfate implant and barrier versus collagen barrier or open flap debridement alone: a 12-month randomized controlled clinical trial. Journal of periodontology. 2008;79(10):1886-1893.

60. Andre-Frei V, Chevallay B, Orly I, Boudeulle M, Huc A, Herbage D. Acellular mineral deposition in collagen-based biomaterials incubated in cell culture media. Calcified tissue international. 2000;66(3):204-211.
61. Bowness JM. Calcium binding by chondroitin sulfate associated with collagen. Biochimica et biophysica acta. 1962;58:134-136.

62. Huang Q, Li C, Zhou Z, Yang J, Shen B, Pei F, et al. [In vitro study of strontium-calcium sulfate compounds as bioactive bone grafted substitute]. Journal of biomedical engineering. 2009;26(3):575-579.

63. Shimabayashi S, Itoi K. Interaction of hydroxyapatite with sodium chondroitin sulfate and calcium chondroitin sulfate in an aqueous phase. Chemical \& pharmaceutical bulletin. 1989;37(6):1437-1440.

64. Park YB, Mohan K, Al-Sanousi A, Almaghrabi B, Genco RJ, Swihart MT, et al. Synthesis and characterization of nanocrystalline calcium sulfate for use in osseous regeneration. Biomed Mater. 2011;6(5):055007.

65. Strocchi R, Orsini G, Iezzi G, Scarano A, Rubini C, Pecora G, et al. Bone regeneration with calcium sulfate: evidence for increased angiogenesis in rabbits. The Journal of oral implantology. 2002;28(6):273-278.

66. Hertzberg BP, Holt JB, Graff RD, Gilbert SR, Dahners LE. An evaluation of carrier agents for desferoxamine, an up-regulator of vascular endothelial growth factor. Journal of biomaterials applications. 2013;27(8):1046-1054.

67. Chang X, Yamada R, Yamamoto K. Inhibition of antithrombin by hyaluronic acid may be involved in the pathogenesis of rheumatoid arthritis. Arthritis research \& therapy. 2005;7(2):R268-273.

68. Dasmah A, Sennerby L, Rasmusson L, Hallman M. Intramembraneous bone tissue responses to calcium sulfate: an experimental study in the rabbit maxilla. Clinical oral implants research. 2011;22(12):14041408.

69. Stubbs D, Deakin M, Chapman-Sheath P, Bruce W, Debes J, Gillies RM, et al. In vivo evaluation of resorbable bone graft substitutes in a rabbit tibial defect model. Biomaterials. 2004;25(20):5037-5044.

70. Walsh WR, Morberg P, Yu Y, Yang JL, Haggard W, Sheath PC, et al. Response of a calcium sulfate bone graft substitute in a confined cancellous defect. Clinical orthopaedics and related research. 2003(406):228-236.

71. Nagata MJ, Furlaneto FA, Moretti AJ, Bouquot JE, Ahn CW, Messora MR, et al. Bone healing in critical-size defects treated with new bioactive glass/calcium sulfate: a histologic and histometric study in rat calvaria. Journal of biomedical materials research Part B, Applied biomaterials. 2010;95(2):269-275.

72. Ohkura N, Enjyoji K, Kamikubo Y, Kato H. A novel degradation pathway of tissue factor pathway inhibitor: incorporation into fibrin clot and degradation by thrombin. Blood. 1997;90(5):1883-1892.

73. Greenberg CS, Shuman MA. Specific binding of blood coagulation factor XIIIa to thrombin-stimulated platelets. The Journal of biological chemistry. 1984;259(23):14721-14727. 
74. Lou Y, Pan Z, Wu R, Xue E, Jiang L, Yang G, et al. [Biocompatibility of alpha-calcium sulfate hemihydrate $(\mathrm{CSH}) /$ multi-walled carbon nanotube (MWCNT) composites for bone reconstruction application]. Chinese journal of biotechnology. 2012;28(3):340-348.

75. La Gatta A, De Rosa A, Laurienzo P, Malinconico M, De Rosa M, Schiraldi C. A novel injectable poly(epsilon-caprolactone)/calcium sulfate system for bone regeneration: synthesis and characterization. Macromolecular bioscience. 2005;5(11):1108-1117.

76. Subramoniam A, Padh H, Aleo JJ. Polymyxin B sulfate-induced pH-dependent increase in calcium influx in cultured fibroblasts. Biochemical medicine and metabolic biology. 1986;35(1):65-71.

77. He X, Dziak R, Mao K, Genco R, Swihart M, Li C, et al. Integration of a novel injectable nano calcium sulfate/alginate scaffold and BMP2 gene-modified mesenchymal stem cells for bone regeneration. Tissue engineering Part A. 2013;19(3-4):508-518.

78. Sollazzo V, Lucchese A, Palmieri A, Carnevali G, Iaccarino C, Zollino I, et al. Calcium sulfate stimulates pulp stem cells towards osteoblasts differentiation. International journal of immunopathology and pharmacology. 2011;24(2 Suppl):51-57.

79. Jung HM, Song GA, Lee YK, Baek JH, Ryoo HM, Kim GS, et al. Modulation of the resorption and osteoconductivity of alpha-calcium sulfate by histone deacetylase inhibitors. Biomaterials. 2010;31(1):29-37.

80. Nyan M, Sato D, Oda M, Machida T, Kobayashi H, Nakamura T, et al. Bone formation with the combination of simvastatin and calcium sulfate in critical-sized rat calvarial defect. Journal of pharmacological sciences. 2007;104(4):384-386.

81. Palmieri A, Pezzetti F, Brunelli G, Scapoli L, Lo Muzio L, Scarano A, et al. Calcium sulfate acts on the miRNA of MG63E osteoblast-like cells. Journal of biomedical materials research Part B, Applied biomaterials. 2008;84(2):369-374.

82. Chen Z, Liu H, Liu X, Lian X, Guo Z, Jiang HJ, et al. Improved workability of injectable calcium sulfate bone cement by regulation of self-setting properties. Materials science \& engineering C, Materials for biological applications. 2013;33(3):1048-1053.

83. Orucoglu H, Cobankara FK. Effect of unintentionally extruded calcium hydroxide paste including barium sulfate as a radiopaquing agent in treatment of teeth with periapical lesions: report of a case. Journal of endodontics. 2008;34(7):888-891.

84. Guo H, Wei J, Liu CS. Development of a degradable cement of calcium phosphate and calcium sulfate composite for bone reconstruction. Biomed Mater. 2006;1(4):193-197.

85. Urban RM, Turner TM, Hall DJ, Infanger SI, Cheema N, Lim TH, et al. An injectable calcium sulfate-based bone graft putty using hydroxypropylmethylcellulose as the plasticizer. Orthopedics. 2004;27(1 Suppl):s155-159.
86. Kelly CM, Wilkins RM. Treatment of benign bone lesions with an injectable calcium sulfate-based bone graft substitute. Orthopedics. 2004;27(1 Suppl):s131-135.

87. Rohmiller MT, Schwalm D, Glattes RC, Elalayli TG, Spengler DM. Evaluation of calcium sulfate paste for augmentation of lumbar pedicle screw pullout strength. The spine journal : official journal of the North American Spine Society. 2002;2(4):255-260.

88. Reynolds MA, Aichelmann-Reidy ME, Kassolis JD, Prasad HS, Rohrer MD. Calcium sulfate-carboxymethylcellulose bone graft binder: Histologic and morphometric evaluation in a critical size defect. Journal of biomedical materials research Part B, Applied biomaterials. 2007;83(2):451-458.

89. Lewis KN, Thomas MV, Puleo DA. Mechanical and degradation behavior of polymer-calcium sulfate composites. Journal of materials science Materials in medicine. 2006;17(6):531-537.

90. Sbordone L, Bortolaia C, Perrotti V, Pasquantonio G, Petrone G. Clinical and histologic analysis of calcium sulfate in treatment of a postextraction defect: a case report. Implant dentistry. 2005;14(1):82-87.

91. Turner TM, Urban RM, Hall DJ, Infanger S, Gitelis S, Petersen DW, et al. Osseous healing using injectable calcium sulfate-based putty for the delivery of demineralized bone matrix and cancellous bone chips. Orthopedics. 2003;26(5 Suppl):s571-575.

92. De Leonardis D, Pecora GE. Prospective study on the augmentation of the maxillary sinus with calcium sulfate: histological results. Journal of periodontology. 2000;71(6):940-947.

93. Thomas MV, Clemens J, Puleo DA. Novel calcium sulfate space-making devices for bone regeneration: a pilot study. Journal of long-term effects of medical implants. 2010;20(4):317-326.

94. Kutkut A, Andreana S, Kim HL, Monaco E, Jr. Extraction socket preservation graft before implant placement with calcium sulfate hemihydrate and platelet-rich plasma: a clinical and histomorphometric study in humans. Journal of periodontology. 2012;83(4):401-409.

95. Shi B, Zhou Y, Wang YN, Cheng XR. Alveolar ridge preservation prior to implant placement with surgical-grade calcium sulfate and plateletrich plasma: a pilot study in a canine model. The International journal of oral \& maxillofacial implants. 2007;22(4):656-665.

96. Intini G, Andreana S, Margarone JE, 3rd, Bush PJ, Dziak R. Engineering a bioactive matrix by modifications of calcium sulfate. Tissue engineering. 2002;8(6):997-1008.

97. Cho BC, Kim TG, Yang JD, Chung HY, Park JW, Kwon IC, et al. Effect of calcium sulfate-chitosan composite: pellet on bone formation in bone defect. The Journal of craniofacial surgery. 2005;16(2):213-24; discussion 25-27.

98. Beenken KE, Smith JK, Skinner RA, McLaren SG, Bellamy W, Gruen- 
wald MJ, et al. Chitosan coating to enhance the therapeutic efficacy of calcium sulfate-based antibiotic therapy in the treatment of chronic osteomyelitis. Journal of biomaterials applications. 2014.

99. Cho BC, Chung HY, Lee DG, Yang JD, Park JW, Roh KH, et al. The effect of chitosan bead encapsulating calcium sulfate as an injectable bone substitute on consolidation in the mandibular distraction osteogenesis of a dog model. Journal of oral and maxillofacial surgery : official journal of the American Association of Oral and Maxillofacial Surgeons. 2005;63(12):1753-1764

100. d'Ayala GG, De Rosa A, Laurienzo P, Malinconico M. Development of a new calcium sulphate-based composite using alginate and chemically modified chitosan for bone regeneration. Journal of biomedical materials research Part A. 2007;81(4):811-820.

101. Zhou Z, Buchanan F, Mitchell C, Dunne N. Printability of calcium phosphate: calcium sulfate powders for the application of tissue engineered bone scaffolds using the 3D printing technique. Materials science \& engineering C, Materials for biological applications. 2014;38:110.

102. Szpalski C, Nguyen PD, Cretiu Vasiliu CE, Chesnoiu-Matei I, Ricci JL, Clark E, et al. Bony engineering using time-release porous scaffolds to provide sustained growth factor delivery. The Journal of craniofacial surgery. 2012;23(3):638-644.

103. Cai S, Zhai Y, Xu G, Lu S, Zhou W, Ye X. Preparation and properties of calcium phosphate cements incorporated gelatin microspheres and calcium sulfate dihydrate as controlled local drug delivery system. Journal of materials science Materials in medicine. 2011;22(11):24872496.

104. Gao C, Huo S, Li X, You X, Zhang Y, Gao J. Characteristics of calcium sulfate/gelatin composite biomaterials for bone repair. Journal of biomaterials science Polymer edition. 2007;18(7):799-824.

105. Qi Y, Wang Y, Yan W, Li H, Shi Z, Pan Z. Combined mesenchymal stem cell sheets and rhBMP-2-releasing calcium sulfate-rhBMP-2 scaffolds for segmental bone tissue engineering. Cell transplantation. 2012;21(4):693-705.

106. Mamidwar S, Weiner M, Alexander H, Ricci J. In vivo bone response to calcium sulfate/poly L-lactic acid composite. Implant dentistry. 2008;17(2):208-216.

107. Mamidwar SS, Arena C, Kelly S, Alexander H, Ricci J. In vitro characterization of a calcium sulfate/PLLA composite for use as a bone graft material. Journal of biomedical materials research Part B, Applied biomaterials. 2007;81(1):57-65

108. Gao C, Gao J, You X, Huo S, Li X, Zhang Y, et al. Fabrication of calcium sulfate/PLLA composite for bone repair. Journal of biomedical materials research Part A. 2005;73(2):244-253.

109. Hesaraki S, Nemati R, Nazarian H. Physico-chemical and in vitro biological study of zinc-doped calcium sulfate bone substitute. Journal of biomedical materials research Part B, Applied biomaterials. 2009;91(1):37-45.

110. Gabriela Fernandes AWB, Rosemary Dziak. The effect of ascorbic acid on bone cancer cells in vitro. Cogent Biology. 2017;3(1).

111. Fernandes G, Vanyo ST, Alsharif SBA, Andreana S, Visser MB, Dziak R. Strontium Effects on Human Gingival Fibroblasts. The Journal of oral implantology. 2019;45(4):274-280.

112. Liu Z, Yuan X, Liu M, Fernandes G, Zhang Y, Yang S, et al. Antimicrobial Peptide Combined with BMP2-Modified Mesenchymal Stem Cells Promotes Calvarial Repair in an Osteolytic Model. Molecular therapy : the journal of the American Society of Gene Therapy. 2018;26(1):199-207.

113. Fernandes G BA, Dziak R. Effects of Verapamil on Bone Cancer Cells in vitro. J Cell Biol Cell Metab. (2016);3.

114. Fernandes G, Yang S. Application of platelet-rich plasma with stem cells in bone and periodontal tissue engineering. Bone research. 2016;4:16036.

115. He X, Dziak R, Yuan X, Mao K, Genco R, Swihart M, et al. BMP2 genetically engineered MSCs and EPCs promote vascularized bone regeneration in rat critical-sized calvarial bone defects. PLoS ONE. 2013;8(4):e60473

116. Liu Z, Yuan X, Fernandes G, Dziak R, Ionita CN, Li C, et al. The combination of nano-calcium sulfate/platelet rich plasma gel scaffold with BMP2 gene-modified mesenchymal stem cells promotes bone regeneration in rat critical-sized calvarial defects. Stem cell research \& therapy. 2017;8(1):122.

117. Fernandes G, Wang C, Yuan X, Liu Z, Dziak R, Yang S. Combination of Controlled Release Platelet-Rich Plasma Alginate Beads and Bone Morphogenetic Protein-2 Genetically Modified Mesenchymal Stem Cells for Bone Regeneration. Journal of periodontology. 2016;87(4):470-480.

118. Pepelassi EM, Bissada NF, Greenwell H, Farah CF. Doxycyclinetricalcium phosphate composite graft facilitates osseous healing in advanced periodontal furcation defects. Journal of periodontology. 1991;62(2):106-115.

119. Conner HD. Bone grafting with a calcium sulfate barrier after root amputation. Compend Contin Educ Dent. 1996;17(1):42.

120. White C, Jr., Bryant N. Combined therapy of mineral trioxide aggregate and guided tissue regeneration in the treatment of external root resorption and an associated osseous defect. Journal of periodontology. 2002;73(12):1517-1521.

121. Di Alberti L, Tamborrino F, Lo Muzio L, D’Agostino A, Trevisiol L, De Santis D, et al. Calcium sulfate barrier for regeneration of human 
bone defects. 3 years randomized controlled study. Minerva stomatologica. 2013.

122. Kim YK, Lee JY, Kim SG, Lim SC. Guided bone regeneration using demineralized allogenic bone matrix with calcium sulfate: case series. The journal of advanced prosthodontics. 2013;5(2):167-171.

123. Pecora G, Andreana S, Margarone JE, 3rd, Covani U, Sottosanti JS. Bone regeneration with a calcium sulfate barrier. Oral Surg Oral Med Oral Pathol Oral Radiol Endod. 1997;84(4):424-429.

124. Yoshikawa G, Murashima Y, Wadachi R, Sawada N, Suda H Guided bone regeneration (GBR) using membranes and calcium sulphate after apicectomy: a comparative histomorphometrical study. Int Endod J. 2002;35(3):255-263.

125. Pecora G, Baek SH, Rethnam S, Kim S. Barrier membrane techniques in endodontic microsurgery. Dental clinics of North America. 1997;41(3):585-602.

126. Favieri A, Campos LC, Burity VH, Santa Cecilia M, Abad Eda C. Use of biomaterials in periradicular surgery: a case report. Journal of endodontics. 2008;34(4):490-494.

127. Borrelli J, Jr., Prickett WD, Ricci WM. Treatment of nonunions and osseous defects with bone graft and calcium sulfate. Clinical orthopaedics and related research. 2003(411):245-254.

128. Drosos GI, Ververidis A, Babourda EC, Kakagia D, Verettas DA Calcium sulfate cement in contained traumatic metaphyseal bone defects. Surgical technology international. 2012;22:313-319.

129. Mik G, Arkader A, Manteghi A, Dormans JP. Results of a minimally invasive technique for treatment of unicameral bone cysts. Clinical orthopaedics and related research. 2009;467(11):2949-2954.

130. Anson D. Saving periodontally "hopeless teeth" using calcium sulfate and demineralized freeze-dried bone allograft. Compend Contin Educ Dent. 1998;19(3):284.

132. Bassett DC, Meszaros R, Orzol D, Woy M, Ling Zhang Y, Tiedemann $\mathrm{K}$, et al. A new class of bioactive glasses: Calcium-magnesium sulfophosphates. Journal of biomedical materials research Part A. 2013.

133. Vorndran E, Geffers M, Ewald A, Lemm M, Nies B, Gbureck U. Ready-to-use injectable calcium phosphate bone cement paste as drug carrier. Acta biomaterialia. 2013;9(12):9558-9567.

134. Yang X, Osagie L, Bostrom MP. In vitro elution characteristics of vancomycin in a composite calcium phosphate/calcium sulfate bone substitute. HSS journal : the musculoskeletal journal of Hospital for Special Surgery. 2012;8(2):129-132.

135. Sultana S, Ali R, Talegaonkar S, Ahmad FJ, Mittal G, Bhatnagar A. In vivo lung deposition and sub-acute inhalation toxicity studies of nano-sized alendronate sodium as an antidote for inhaled toxic substances in Sprague Dawley rats. Environmental toxicology and pharmacology. 2013;36(2):636-647.

136. Gupta GK, Kumar A, Khedgikar V, Kushwaha P, Gautam J, Nagar GK, et al. Osteogenic efficacy enhancement of kaempferol through an engineered layer-by-layer matrix: a study in ovariectomized rats. Nanomedicine (Lond). 2013;8(5):757-771.

137. Simson J, Crist J, Strehin I, Lu Q, Elisseeff JH. An orthopedic tissue adhesive for targeted delivery of intraoperative biologics. Journal of orthopaedic research : official publication of the Orthopaedic Research Society. 2013;31(3):392-400.

138. Hou S, Nicholson L, van Niekerk E, Motsch M, Blesch A. Dependence of regenerated sensory axons on continuous neurotrophin-3 delivery. The Journal of neuroscience : the official journal of the Society for Neuroscience. 2012;32(38):13206-13220.

139. Bae SE, Choi J, Joung YK, Park K, Han DK. Controlled release of bone morphogenetic protein (BMP)-2 from nanocomplex incorporated on hydroxyapatite-formed titanium surface. Journal of controlled release : official journal of the Controlled Release Society. 2012;160(3):676-684.

140. Lee DW, Yun YP, Park K, Kim SE. Gentamicin and bone morphogenic protein-2 (BMP-2)-delivering heparinized-titanium implant with enhanced antibacterial activity and osteointegration. Bone. 2012;50(4):974-982.

141. Abdelkebir K, Gaudiere F, Morin-Grognet S, Coquerel G, Atmani $\mathrm{H}$, Labat B, et al. Protein-triggered instant disassembly of biomimetic Layer-by-Layer films. Langmuir : the ACS journal of surfaces and colloids. 2011;27(23):14370-14379.

142. Zhao J, Shen G, Liu C, Wang S, Zhang W, Zhang X, et al. Enhanced healing of rat calvarial defects with sulfated chitosan-coated calciumdeficient hydroxyapatite/bone morphogenetic protein 2 scaffolds. Tissue engineering Part A. 2012;18(1-2):185-197.

143. Gogia JS, Meehan JP, Di Cesare PE, Jamali AA. Local antibiotic therapy in osteomyelitis. Seminars in plastic surgery. 2009;23(2):100107.

144. Beuerlein MJ, McKee MD. Calcium sulfates: what is the evidence? Journal of orthopaedic trauma. 2010;24 Suppl 1:S46-51.

145. Kutkut A, Andreana S. Medical-grade calcium sulfate hemihydrate in clinical implant dentistry: a review. Journal of long-term effects of medical implants. 2010;20(4):295-301.

146. Jia WT, Luo SH, Zhang CQ Wang JQ. In vitro and in vivo efficacies of teicoplanin-loaded calcium sulfate for treatment of chronic methicillin-resistant Staphylococcus aureus osteomyelitis. Antimicrobial agents and chemotherapy. 2010;54(1):170-176. 
147. Hesaraki S, Moztarzadeh F, Nezafati N. Evaluation of a bioceramic-based nanocomposite material for controlled delivery of a non-steroidal anti-inflammatory drug. Medical engineering \& physics. 2009;31(10):1205-1213.
148. Mamidwar. Calcium sulfate use in dentistry. Dental implantology update. 2009;20(5):38-40. 